\title{
LA RESPONSABILIDAD CIVIL COMO FORMA DE APLICACIÓN PRIVADA DEL DERECHO DE LA COMPETENCIA
}

\section{LIABILITY AS A FORM OF PRIVATE IMPLEMENTATION OF COMPETITION LAW}

\section{LA RESPONSABILITÉ CIVILE COMME FORME D'APPLICATION PRIVÉE DU DROIT DE LA CONCURRENCE}

\author{
Cristián Banfi del Río*
}

\section{RESUMEN}

Este artículo incursiona en la aplicación por los particulares de las normas sobre libre competencia, concentrándose en una de sus expresiones concretas: la responsabilidad civil extracontractual, especialmente entre rivales. Valiéndose de elementos de Derecho extranjero y chileno, muestra que la responsabilidad aquiliana hace una contribución limitada a la prevención y sanción de las conductas anticompetitivas. Primero, los atentados a la libre competencia dañan principalmente a los consumidores y a los mercados como un todo, en tanto la responsabilidad civil es un instrumento esencialmente compensatorio del perjuicio que dichas conductas infligen a víctimas individuales e identificables, como los competidores. Enseguida, la compleja prueba del daño y de la causalidad restringe considerablemente la posibilidad de obtener un resarcimiento, reduciendo la eficacia de la responsabilidad civil como un medio disuasivo de las conductas anticompetitivas.

Palabras claves: responsabilidad civil, aplicación privada del Derecho de la Competencia

* Profesor asociado de Derecho Civil, Universidad de Chile. Correo electrónico: cbanfi@asyc.com. Dirección postal: Pío Nono 1, Providencia, Santiago. Artículo recibido el 5 de agosto de 2013 y aceptado para su publicación el 21 de octubre de 2013.

Este artículo integra el Proyecto FONDECYT de iniciación N 11121336 "Revisión crítica de la responsabilidad civil por daños entre competidores por conductas anticompetitivas en Chile". 


\begin{abstract}
This article tackles private antitrust enforcement, focusing on one of its concrete expressions: tort liability, in particular between rivals. Using elements of foreign and Chilean law, this article shows that tort liability makes a limited contribution to the deterrence and punishment of anticompetitive conduct. First, antitrust infringements impair mainly consumers and markets as a whole, whilst tort liability is esentially an instrument of compensation for the harm that those acts inflict on individual and identifiable victims, like competitors. Secondly, the complex proof of harm and causation significantly restricts the chance of obtaining redress, thus diminishing the effectiveness of tort liability as a deterrent to anticompetitive behaviour.
\end{abstract}

Key words: Tort liability, Private antitrust enforcement

\title{
RÉSUMÉ
}

Cet article se penche sur l'application par les particuliers des normes régissant 218 la libre concurrence et se concentre sur une de ses expressions concrètes, à savoir la responsabilité civile extracontractuelle, en particulier entre concurrents. Sur la base d'éléments du droit étranger et du droit chilien, cette étude démontre que la responsabilité aquilienne apporte une contribution limitée à la prévention et à la sanction des comportements anticoncurrentiels. En premier lieu, les atteintes à la libre concurrence ont surtout des effets néfastes sur les consommateurs et sur les marchés dans leur ensemble, et la responsabilité civile est un instrument essentiellement compensatoire du préjudice causé par ces comportements à des victimes individuelles et identifiables, comme les concurrents. En deuxième lieu, la preuve complexe du dommage et de la causalité restreint considérablement la possibilité d'obtenir une réparation, limitant ainsi l'efficacité de la responsabilité civile comme moyen de dissuasion des comportements anticoncurrentiels

Mots clés: Responsabilité civile, Application privée du droit de la concurrence.

\section{INTRODUCCIÓN}

1. La relevancia de la competencia para el progreso económico es patente en la moderna legislación comunitario-europea, angloamericana y 
chilena. Los ordenamientos jurídicos adscritos a economías de mercado consideran atentatorias a la libre competencia a las mismas conductas, fundamentalmente, los acuerdos colusorios (carteles), las prácticas concertadas y el abuso de posición dominante. Así, la legislación federal estadounidense $^{1}$ sanciona tanto las colusiones, combinaciones o concertaciones que distribuyen su enorme poderío económico y político entre un sinnúmero de pequeños y medianos productores ${ }^{2}$, como los abusos de posición dominante o monopolización ${ }^{3}$. Por su parte, $\mathrm{TFUE}^{4}$ declara incompatibles con el mercado interior y prohíbe

"los acuerdos entre empresas, las decisiones de asociaciones de empresas y las prácticas concertadas que puedan afectar al comercio entre los Estados Miembros y que tengan por objeto o efecto impedir, restringir o falsear el juego de la competencia dentro del mercado interior" ${ }^{5}$

y -en la medida que afecte el comercio entre los Estados Miembros-

"la explotación abusiva, por parte de una o más empresas, de una posición dominante en el mercado interior o en una parte sustancial del mismo" ${ }^{6}$.

A su vez, en el Reino Unido la Competition Act, de 1998 -modificada por la Enterprise Act, de 2002- prohíbe los acuerdos que tienen por objetivo o efecto impedir, restringir o falsear la libre competencia (capítulo I) y el

${ }^{1}$ Sherman Act, de 1890. Ésta ha sido llamada la Carta Magna de la libre empresa: U.S. v. Topco Associates, Inc. (1972), p. 610, juez Thurgood Marshall.

2 "Todo contrato, combinación en forma de trust o de otra clase, o conspiración restrictiva del tráfico o del comercio entre los estados o con países extranjeros": $\S 1$ Sherman Act, de 1890.

${ }^{3}$ Es "reo de delito punible toda persona que monopolice o trate de monopolizar cualquier parte de la actividad o el comercio entre o los diversos estados o con naciones extranjeras y toda persona que se coaligue o entre en combinación con cualquier otra persona o personas para monopolizar cualquier parte del comercio entre los estados federados o con otros países": § 2 Sherman Act, de 1890. El o los autores de los acuerdos colusorios o de actos de monopolización pueden ser condenados, a discreción del tribunal, a penas privativas de libertad de hasta tres años, a multas máximas de US\$350.000 o US\$10.000.000 o ambas, según si son personas naturales o jurídicas, respectivamente.

${ }^{4}$ El tratado de Lisboa, de 2007, modificó el tratado de la Unión Europea y sustituyó el tratado de Roma de 1957, constitutivo de la Comunidad Europea ("Tratado CE"), por el TFUE. Los arts. 81 y 82 del Tratado CE fueron reemplazados por los arts. 101 y 102 del TFUE, respectivamente. En este trabajo se utiliza en exclusiva esta nueva numeración.

${ }^{5}$ Art. $101 \mathrm{~N}^{\circ} 1$ del TFUE.

${ }^{6}$ Art. 102 del TFUE. 
abuso de posición dominante en el mercado relevante (capítulo II) ${ }^{7}$. En fin, el art. $3^{\circ}$ inc. $1^{\circ}$ del DL $N^{\circ} 211$, de 1973 define el ilícito anticompetitivo como

"cualquier hecho, acto o convención que impida, restrinja o entorpezca la libre competencia, o que tienda a producir dichos efectos"

y en su inc. $2^{\circ}$ describe tres ejemplos:

- los acuerdos entre competidores o las prácticas concertadas entre éstos, v.gr., aquéllas que fijan precios de venta o compra;

- la explotación abusiva por uno o más agentes económicos de una posición dominante en el mercado y

- las prácticas predatorias o de competencia desleal tendientes a alcanzar, conservar o incrementar una posición dominante.

2. En diversos sistemas jurídicos existen entes públicos encargados de aplicar las normas sobre libre competencia, investigando las infracciones e imponiendo las sanciones respectivas. Esto conforma el modelo públicoadministrativo o public enforcement. Entres dichos organismos destacan la Antitrust Division (Departament of Justice) y la Federal Trade Commission estadounidenses; la Comisión Europea; la OFT y el CAT británicos y la 220 FNE, el TDLC y la CS chilenas.

3. Sin embargo, los particulares también desempeñan un papel relevante en la aplicación del Derecho de la Competencia, en cuyo caso se habla del modelo privado de aplicación de la ley o private enforcement. Este último -traducido al español como "aplicación privada del Derecho de la Competencia"- proviene del sistema estadounidense. En Estados Unidos los mecanismos privados de protección de la libre competencia han devenido tan robustos que aproximadamente el 90\% de los pleitos por ilícitos anticompetitivos son impulsados por particulares ${ }^{8}$. Desde luego, esta circunstancia obedece, en gran medida, a la existencia de incentivos formidables, como el derecho de toda persona cuyo negocio o propiedad ha sido afectada por conductas antitrust a obtener hasta el triple de los daños sufridos (treble damages), más las costas del juicio y los honorarios razonables de los abogados ${ }^{9}$. La idea es que los particulares asuman un

${ }^{7}$ El art. 60 de la Competition Act, de 1998, obliga a los jueces a interpretar esta ley conforme al Derecho Comunitario. Además, las reglas nacionales y comunitarias suelen superponerse: SLOANE y GREGORY (2005), pp. 22-23.

${ }^{8}$ Salop y White (1986), pp. 1001-1052; Hylton (2003), p. 56; Foer (2011), pp. 206-207.

${ }^{9}$ Sección cuarta, Clayton Act, de 1914. Precisamente la tercera parte de estos daños es de carácter punitivo: Posner (2003), p. 328. Los treble damages fueron introducidos en Inglaterra como defensa frente a demandas de cumplimiento de contratos anticompetitivos. En Darcy v. Allein (1572) un monopolio de juego de cartas otorgado por la reina Isabel 
papel activo no sólo en la indemnización de los daños derivados de los ilícitos anticompetitivos sino, también, en la persecución y sanción de los infractores así como en la disuasión de dichas conductas ${ }^{10}$.

En contraste, en Europa el private enforcement en general, y las acciones indemnizatorias por daños derivados de conductas anticompetitivas en particular, han tenido un tímido desarrollo. En las últimas décadas se viene proponiendo que el TEJ conceda directamente acciones para ejercer el derecho a la reparación de tales daños y que se codifiquen los principios de responsabilidad aquiliana para extender el private enforcement uniformemente en el Viejo Continente ${ }^{11}$. Con todo, todavía no existen normas vinculantes para todos los Estados Miembros de la Unión Europea, cuyas notorias diferencias sustantivas y procesales los distancian entre sí. Esto, a su vez, genera un explicable escepticismo acerca de la factibilidad de implementar una regulación homogénea en Europa ${ }^{12}$. Empero, la reciente propuesta de directiva sobre daños por ilícitos anticompetitivos constituye un avance significativo hacia tan anhelada armonización ${ }^{13}$.

4. En sentido amplio, el private enforcement comprende todas las acciones ejercidas por particulares, sea para denunciar los ilícitos anticoncurrenciales ante las autoridades públicas correspondientes, sea para hacer valer los efectos civiles o patrimoniales que se siguen de dichas conductas ${ }^{14}$. De esta manera, el private enforcement incluye diversos mecanismos de protección. Por un lado, los particulares pueden interponer demandas o presentar denuncias ante las autoridades administrativas pertinentes para que se investigue la comisión de supuestas conductas anticompetitivas y eventualmente se castigue a los infractores, con multas o penas privativas de libertad, según cual sea la jurisdicción implicada. Este derecho está previsto, sin ir más lejos, en el art. 20 del DL No 211. Por otro lado, los particulares pueden interponer acciones civiles preventivas (medidas cautelares -o injunctions en los sistemas angloamericanos- para impedir la perpetración de conductas anticoncurrenciales o hacer cesar aquéllas iniciadas), acciones de nulidad de los acuerdos o contratos contrarios a la

I fue calificado como ilícito. En Mitchell v. Reynolds (1712) el pacto en que una persona se obliga a no ejercer una actividad económica absolutamente o en cierta localidad, salvo que concurra una causa (consideration) razonable, fue declarado nulo por estimarse que vulneraba el interés público. Los treble damages fueron consagrados en el Statute of Monopolies, de 1623 y abolidos por el Statute Law (Repeals) Act, de 1969: Jones (1999), pp. 35-36; Treitel (2007), p. 713; Crane (2011), pp. 50-51.

${ }^{10}$ Brunswick Corp. v. Pueblo Bowl-O-Mat, Inc. (1977), pp. 486-487.

${ }^{11}$ Claydon (1983), pp. 245-252; Friend y Shaw (1984), pp. 188-192; Jones (1999), p. 245 y ss.; Drake (2006), pp. 857-858; VAn Gerven (2007), pp. 19-38.

${ }^{12}$ Komninos (2008), p. 142 y ss.

${ }^{13}$ COM (2013), 404 final.

${ }^{14}$ Komninos (2008), p. 1. 
libre competencia y acciones de indemnización de los perjuicios emanados de los ilícitos antitrust, posibilidad, esta última, contemplada expresamente en el art. 30 del DL N ${ }^{o} 211^{15}$. En palabras de un jurista chileno, el private enforcement consiste en:

"la intervención de los particulares en la aplicación del Derecho de la competencia, tema dentro del cual el estudio del sistema compensatorio de las víctimas es uno de los pilares" ${ }^{16}$.

En sentido restringido, en cambio, el private enforcement concierne exclusivamente a las acciones civiles (cautelares, de nulidad y resarcitorias) interpuestas ante los tribunales civiles, originadas en conductas anticompetitivas, y la interpretación y aplicación que dichos órganos jurisdiccionales hacen de las normas pertinentes. Esta perspectiva resalta la vinculación entre el Derecho de la Competencia y el Derecho Privado:

"El private enforcement se define como el sistema de aplicación de las normas de libre competencia a cargo de los jueces civiles, que tiene lugar dentro de los litigios que se promueven entre particulares y en los que éstos buscan hacer efectivos los derechos que les conceden los arts. 101 y 102 del TFUE y/o las normas nacionales...El núcleo del sistema de private enforcement reside en la declaración de los efectos civiles o efectos jurídico-privados que derivan de la infracción de las normas de libre competencia, esto es, la nulidad absoluta y la responsabilidad civil de los infractores. La definición de estos efectos materializa la conexión y la aproximación del Derecho antitrust al Derecho civil; evidencia además la finalidad protectora de las normas de competencia, el papel que corresponde desarrollar a los particulares en el control de las conductas restrictivas, las funciones de garante que se hallan a cargo de los jueces nacionales y la necesaria coordinación y cooperación de éstos con las autoridades administrativas" ${ }^{17}$.

15 "La acción de indemnización de perjuicios a que haya lugar, con motivo de la dictación por el Tribunal de Defensa de la Libre Competencia de una sentencia definitiva ejecutoriada, se interpondrá ante el tribunal civil competente de conformidad a las reglas generales, y se tramitará de acuerdo al procedimiento sumario, establecido en el Libro III del Título XI del Código de Procedimiento Civil. // El tribunal civil competente, al resolver sobre la indemnización de perjuicios, fundará su fallo en las conductas, hechos y calificación jurídica de los mismos, establecidos en la sentencia del Tribunal de Defensa de la Libre Competencia, dictada con motivo de la aplicación de la presente ley".

${ }^{16}$ Araya (2005), p. 16.

${ }^{17}$ Ortíz (2011), pp. 29-30. 
5. Las acciones privadas para hacer cumplir el Derecho de la Competencia (denuncias ante los órganos competentes, medidas cautelares, demandas de nulidad y acciones indemnizatorias) interactúan con la aplicación de aquél por las autoridades administrativas. Los instrumentos privados pueden operar $-\mathrm{y}$ a menudo funcionan- como medios auxiliares para perseguir, disuadir y sancionar los comportamientos anticompetitivos, promoviendo el respeto de las normas de libre competencia ${ }^{18}$. Si bien la autoridad pública debe perseguir el cumplimiento de la ley, constatar las transgresiones y castigar a los culpables ${ }^{19}$, la amenaza de denunciar tanto un presunto ilícito anticompetitivo como de iniciar un litigio civil tendiente a conseguir medidas cautelares, compensaciones en dinero, la nulidad de convenciones anticompetitivas o la restitución de utilidades obtenidas de forma injusta por los infractores, puede contribuir a la disuasión de los ilícitos antitrust ${ }^{20}$.

En Estado Unidos existe evidencia empírica no sólo de que las normas sustantivas que prohíben conductas influyen en el volumen de litigación y que ciertas reglas procesales frenan la interposición de demandas infundadas sino, también, de que las diversas acciones privadas antes mencionadas coadyuvan a la prevención de los atentados a la libre competencia ${ }^{21}$. Estas acciones complementan el public enforcement, que es necesariamente selectivo, incrementando la probabilidad de descubrir y sancionar las infracciones y desincentivar su perpetración, supuesto que el costo de violar la ley (representado por las multas e indemnizaciones) sea suficientemente elevado ${ }^{22}$. La sinergia entre los litigantes privados y los persecutores públicos es notable en el sistema estadounidense, donde la prevención del ilícito anticompetitivo ocupa un lugar primordial mientras que la reparación del daño padecido por las víctimas particulares es una meta secundaria ${ }^{23}$.

6. El presente artículo concibe el private enforcement en su sentido extenso, pero pone el énfasis en las acciones de indemnización de los daños que los actos anticoncurrenciales causan a particulares, sobre todo a rivales. $\mathrm{Al}$ respecto cabe señalar que -en principio- todo operador económico (consumidor, proveedor, competidor, etc.) tiene derecho a obtener el resarcimiento del daño sufrido a consecuencia de conductas antitrust. Así lo

${ }^{18}$ Heydon (1980), p. 135; Weir (2004), p. 598; Komninos (2008), p. 6.

${ }^{19}$ Möllers and Heinemann (2007), pp. 389 y 661; Whish (2007), pp. 50-51.

${ }^{20}$ YeUnG (1998), pp. 581-615; Jones (2004), pp. 13-24.

${ }^{21}$ SALOP and White (1986).

${ }^{22}$ Areeda et al. (2004), p. 58.

23 "Un sistema de prevención bien diseñado reducirá a un nivel bajo la incidencia de las infracciones y ....aseguraría como un efecto colateral una indemnización adecuada salvo que el costo de administrar la indemnización sea prohibitivo": Posner (2001), p. 266. 
reconocen la sección cuarta de la Clayton Act, de 1914, la jurisprudencia del TEJ ${ }^{24}$ (ante el mutismo de los arts. 101 y 102 del TFUE $^{25}$ ), las leyes internas de los Estados Miembros de la Unión Europea ${ }^{26}$ y, por cierto, nuestro derecho, incluso antes de que existiera el art. 30 del DL No $211^{27}$. Este trabajo se concentra en el daño indemnizable o resarcible en sede civil, esto es, la lesión de un derecho subjetivo o interés legítimo en la persona o bienes de la víctima, ya consista en un perjuicio económico (típicamente daño patrimonial puro $)^{28}$ o moral ${ }^{29}$. Este perjuicio difiere del

${ }^{24}$ Courage Ltd. v. Crehan (2001); Manfredi v. Lloyd Adriatico Assicurazioni SpA (2006). En estos casos el TEJ delegó en las legislaciones nacionales la definición de las reglas sustantivas y procesales para ejercer el derecho a la reparación de los daños causados por conductas anticompetitivas: WHISH and BAILEY (2012), p. 300. Así como los Estados Miembros de la Unión Europea deben responder del daño causado por contravenir normas comunitarias que no tienen efectividad directa [Francovich v. The Republic of Italy (1991)], con mayor razón los individuos deben responder de los daños que causan mediante la infracción de normas que gozan de tal eficacia, como los arts. 101 y 102 del TFUE: Whish (1994), p. 64. En Courage el TEJ determinó que una de las partes de un contrato anticompetitivo puede demandar a la otra la indemnización de los perjuicios sufridos a consecuencia de aquél. Asimismo, resolvió que las reglas in pari delicto, esto es, "si ambas partes actúan contra derecho el demandado prevalece" -Langton v. Hughes (1813), Boissevain v. Weil (1950), Gibbs Mew Plc v. Gemmell (1998) - y ex turpi causa -las partes 224 de un contrato ilegal no pueden reclamar la indemnización de daños ni la restitución de lo dado o pagado: Holman v. Johnson (1775); VIRGO (2006), p. 721 y ss.--, son coherentes con el Derecho Comunitario si sólo se aplican al contratante que tuvo una responsabilidad significativa en la infracción, según el contexto económico-jurídico y el poder de negociación de cada parte: Courage Ltd. v. Crehan (2001), §§ 32-36; EdELman and Odudu (2002), pp. 327339; Andreangeli (2004), pp. 758-764. El TEJ emuló lo resuelto por la CS estadounidense en Perma-Life Mufflers, Inc. v. International Parts Corp (1968) que rechazó la defensa in pari delicto opuesta por el contratante económicamente fuerte que tuvo influencia gravitante en la comisión del ilícito anticoncurrencial:JonEs (1999), p. 130 y ss.; STANTON et al. (2003), pp. 22-23 y 414; Rodger (2003), pp. 103-104; StANTON (2004), pp. 324-341.

${ }^{25}$ La jurisprudencia anglosajona allanó el camino para el ulterior reconocimiento en Europa del derecho a la reparación del daño emanado de ilícitos antitrust: Garden Cottage Foods Ltd. v. Milk Marketing Board (1983).

${ }^{26}$ Así, la sección 47A de la Competition Act, de 1998, faculta al afectado para reclamar ante el CAT los perjuicios derivados de infracciones anticoncurrenciales declaradas por la Comisión Europea o la OFT.

27 "La posibilidad de interponer esta acción, que desde siempre ha estado abierta a los particulares en conformidad a la normativa general del Código Civil, vino a ser consagrada de manera expresa y con particularidades en el art. 30 del DL N ${ }^{\circ} 211$ en virtud de la modificación del año 2003...”: ArAYA (2005), p. 11. El primer litigio patrio sobre responsabilidad civil por conductas anticompetitivas siguió a una condena impuesta por la ex Comisión Resolutiva y se basó únicamente en el art. 2314 y ss. del CC: Pivcevic y otros con LAN Chile (2006).

${ }^{28}$ BANFi (2012a), pp. 685-704.

${ }^{29}$ V. gr., Sociedad General de Comercio S.A. con Banco Español-Chile (1954); Contra Vergara Pérez, José Eugenio (1972); Contra Suárez S., Roberto (1973); Domínguez (1990), 
"daño anticompetitivo" o costo social neto que acarrean las infracciones a la libre competencia. El daño anticompetitivo comporta una reducción tanto en la cantidad como en la calidad de los bienes y servicios disponibles, precios por sobre los niveles competitivos, etcétera ${ }^{30}$.

\section{ACCIONES INDEMNIZATORIAS Y DAÑOS PUNITIVOS}

1. Las acciones civiles resarcitorias constituyen uno de los principales mecanismos privados para defender la libre competencia. Sin embargo, se hace necesario distinguirlas de los daños punitivos, ejemplares o extracompensatorios, como son los treble damages contemplados en la Clayton Act. Éstos conforman uno de los incentivos más potentes del private enforcement, aunque son objeto de una intensa discusión. Para sus detractores, los daños triples exacerban la litigación irresponsable; desalientan la autodenuncia de infracciones lo que menoscaba los programas de clemencia o delación compensada que son esenciales para desarmar los carteles; y no promueven el deber de las víctimas de evitar o mitigar sus pérdidas. Así las cosas, sería preferible que el regulador determine el nivel óptimo del castigo por la vía de incrementar o reducir las multas ${ }^{31}$. En cambio, para otro grupo de académicos los daños triples proporcionan una recompensa monetaria que estimula la litigación privada en directo beneficio de la prevención y sanción de los ilícitos anticoncurrenciales ${ }^{32}$.

2. Una de las dificultades más arduas concierne a la cuantificación de las multas e indemnizaciones en forma que prevengan las conductas antitrust sin desalentar las actividades eficientes ${ }^{33}$. El Derecho desincentiva estos comportamientos haciendo onerosa su ejecución. Pero la cuestión es cuán costosa ella debe ser para que no prevenga más ni menos que el daño anticompetitivo soportado por los consumidores ${ }^{34}$. La idea matriz es que mientras menor sea la chance de detectar y sancionar al infractor mayor debe ser la pena ${ }^{35}$ :

pp. 125 y 128; Diez (1997), pp. 21 y 34; Corral (2003), pp. 138 y 146; Barros (2006), p. 221 y ss.

30 Araya (2005), pp. 21-23.

${ }^{31}$ Breit and Elzinga (1974), pp. 329-356; Baumol and Ordover (1985), p. 253; SAloP and White (1986), pp. 1049-1052; SNYder and KaUper (1991), p. 596 y ss.; Robin (2005), pp. 52-77; Waelbroeck and Slater (2007), pp. 425-445.

${ }^{32}$ Polinsky (1986), pp. 1231-1236; Areeda and Kaplow (1997), p. 73 y ss.; Rodger (2003), pp. 104-105; Holmes (2004), pp. 35-36; Paulis (2007), p. 12 y ss.

${ }^{33}$ PAGE (1980), pp. 467-504.

${ }^{34}$ Posner (2001), p. 267.

${ }^{35}$ Op. cit., p. 271. 
"la desventaja del castigo debería exceder a la ventaja que se espera obtener con el crimen; y tal exceso debería incluir el cálculo de la certeza de que se castigue y la pérdida del beneficio esperado" 36 .

Las multas y daños punitivos suelen ser un instrumento disuasorio eficiente si su monto es inversamente proporcional a la probabilidad de descubrir al transgresor ${ }^{37}$.

Para lograr el óptimo de prevención la norma debe provocar que el infractor internalice los costos sociales que su actividad comportará y los coteje con la probabilidad de ser castigado ${ }^{38}$. En un escenario utópico -sin costos de enforcementy con una probabilidad de sancionar las conductas ilícitas igual a uno- la multa óptima equivale al costo social neto sufrido por los consumidores y a la transferencia de riqueza de éstos hacia los infractores ${ }^{39}$. No obstante, en la realidad las multas e indemnizaciones deben ser calibradas según la posibilidad concreta de sancionar a los culpables. Pues bien, un tercio de los treble damages refleja la probabilidad de detectar el ilícito; pero como este porcentaje es insuficiente para perseguir actividades clandestinas como los carteles, los daños punitivos se presentan como una posible solución. En cambio, tratándose de comportamientos más ostensibles como la exclusión de rivales, los daños punitivos pueden elevar por sobre el óptimo 226 la prevención y la probabilidad de descubrir la conducta anticompetitiva ${ }^{40}$. El nivel óptimo de precaución podría alcanzarse si el importe de los daños punitivos correspondiera al perjuicio sufrido por la víctima multiplicado por un factor que representara la probabilidad de que el infractor eluda su responsabilidad, con independencia de la gravedad del ilícito y de la solvencia del hechor ${ }^{41}$. También se aconseja establecer una suma mínima a título de daños punitivos que refleje la probabilidad de sancionar e imputar responsabilidad civil al infractor. Cuando la ganancia obtenida por el infractor supera el daño padecido por la víctima, los daños punitivos cumplen una función retributiva al obligar a aquél a internalizar dicha pérdida; en caso contrario, los daños punitivos serían una herramienta preventiva ${ }^{42}$.

${ }^{36}$ BECCARIA (1996), pp. 49-50. "El valor de la pena no debe ser menor en caso alguno de lo que es suficiente para contrapesar el valor de la ganancia del crimen": Beccaria's Dei Delitti e Delle Pene, § 6 (trad. francesa por André Morellet), citada por Bentham (1996), § 8 , p. 166. Para Jeremy Bentham si la infracción es perpetrada de todos modos, el castigo sería completamente inoficioso: $i b i d$.

${ }^{37}$ Baumol and Ordover (1985), p. 263.

${ }^{38}$ Becker (1968), pp. 169-217.

${ }^{39}$ Hylton (2003), p. 44.

${ }^{40}$ Landes and Posner (1975), pp. 1-46; Posner (2001), p. 272.

${ }^{41}$ Polinsky and Shavell (1998), pp. 954-955.

${ }^{42}$ Hylton (1998), pp. 421-471. 
3. Con todo, es incierto si la amenaza de una acción tanto indemnizatoria como de daños punitivos completa la siempre insuficiente disuasión de conductas soterradas como los acuerdos colusorios ${ }^{43}$. Parte de la doctrina considera necesario eliminar o reducir las multas, indemnización de perjuicios y daños punitivos para resguardar la confidencialidad de la información reunida por la autoridad administrativa en investigaciones originadas en autodenuncias, cautelando los programas de clemencia y la detección de carteles ${ }^{44}$. En Estados Unidos, en principio los conspiradores son solidariamente responsables de los daños causados a terceros sin derecho a contribución entre si $^{45}$. El impacto de esta regla en la disuasión es materia de desavenencias ${ }^{46}$. Sin embargo, para evitar que las acciones indemnizatorias y de daños punitivos inhiban a los infractores a denunciar sus conductas, la Antitrust Criminal Penalty Enhancement and Reform Act, de 2004, limita la responsabilidad del autodenunciante a los daños efectivos, eximiéndole del pago de los treble damages y de responder de forma solidaria con los demás coautores ${ }^{47}$.

Por su parte, algunos juristas europeos son partidarios de premiar al denunciante mediante una rebaja de las multas y la confidencialidad de sus declaraciones, pero sin exonerarlo de su responsabilidad civil ${ }^{48}$. Recientemente el TEJ negó al actor acceso a información del autodenunciante de un cartel cuyos miembros habían sido multados. El tribunal consideró que la divulgación de solicitudes de clemencia pone en riesgo el public enforcement de los carteles. Empero, el tribunal estimó necesario fortalecer las acciones privadas, delegando en los órganos jurisdiccionales nacionales la determinación de la forma cómo deben interactuar los instrumentos públicos y privados de protección de la libre competencia ${ }^{49}$.

4. Un sector de la doctrina inglesa promueve los daños punitivos como medio de prevenir los ilícitos antitrust-particularmente los más severos-y

${ }^{43}$ Hylton (2003), p. 52.

${ }^{44}$ Peretz (2005), p. 82; Terhechte (2011), pp. 19-20.

${ }^{45}$ Texas Industries, Inc. v. Radcliff Materials, Inc. (1981).

${ }^{46}$ Por un lado, se sostiene que al eliminarse la contribución la responsabilidad potencial por el daño causado por los co-conspiradores incrementa la disuasión y estimula las transacciones no sólo como un medio efectivo de indemnizar a las víctimas sino, también, como una forma de cooperación para el descubrimiento del ilícito: EASTERBROOK et al. (1980), pp. 331-370; Polinsky and Shavell (1981), pp. 447-471. En contra, se aduce que si cada coautor está expuesto a indemnizar la totalidad del daño, aunque su participación haya sido irrelevante, se verá forzado a transigir para evitar ese riesgo. A su vez, los actores también pueden verse presionados a transigir por un monto bajo, incluso con los coautores más culpables: AREEDA et al. (2004), p. 60.

${ }^{47}$ Goldberg y Gustafson (2012), pp. 172-173.

${ }^{48}$ Heinemann (2011), pp. 224-225.

${ }^{49}$ Pfleiderer AG v. Bundeskartellamt (2011), §§ 25-31; WHISH y BAILEY (2012), pp. 305-306. 
de evitar el enriquecimiento injusto de los infractores ${ }^{50}$, que es una de las situaciones en que de modo excepcional el Common Law admite los daños punitivos $^{51}$. También se reconoce en la restitución de ganancias ilícitas un mecanismo disuasorio incluso más eficaz que la indemnización del daño atendida la enorme dificultad que encierra la prueba de este último ${ }^{52}$. Sin embargo, recientemente los daños punitivos fueron desestimados por estimarse que vulneraban el non bis in ídem: los demandados -que lucraron con su cartel- habían sido multados por la Comisión Europea, aunque, en definitiva, nada pagaron al operar en su favor la delación compensada ${ }^{53}$. En general, la jurisprudencia inglesa acepta los daños punitivos respecto de ilícitos serios siempre que sus autores no hayan sido sancionados por la autoridad administrativa ${ }^{54}$.

5. En los sistemas jurídico-continentales los daños punitivos contradicen la función indemnizatoria de la responsabilidad civil y pueden ser una fuente de enriquecimiento injusto para los actores en la medida que éstos (y no el erario público) perciban sumas por sobre el daño sufrido ${ }^{55}$. Tampoco es necesario introducir los daños punitivos, pues el ordenamiento contempla multas suficientemente disuasorias de los actos antitrust cuyo monto puede aumentarse en ciertas circunstancias. Las acciones indemnizatorias serían el único complemento privado requerido para lograr un nivel razonable de enforcement. Asimismo, los daños punitivos promoverían una litigación especulativa y ello desincentivaría la denuncia de los carteles en detrimento de los programas de delación compensada. Por último, si bien los infractores a menudo lucran en exceso del daño sufrido por las víctimas, la restitución de las utilidades percibidas de forma injusta no debe buscarse a través de una institución compensatoria, como la responsabilidad civil, sino que debe perseguirse mediante el principio que prohíbe el enriquecimiento injusto, por ejemplo, agravando las multas a beneficio fiscal ${ }^{56}$. Por su parte, el TEJ ha declarado que cada Estado Miembro debe

${ }^{50}$ Kuddus v. Chief Constable of Leicestershire (2001), § 66, juez Lord Nicholls; RoDGER (2003), p. 109 y ss.; BEARD (2005), pp. 283-284; BuXBAum (2007), pp. 41-60; Odudu y Virgo (2009), pp. 32-35; Sheehan (2009), pp. 222-226.

${ }^{51}$ Rookes v. Barnard (1964).

${ }^{52}$ Devenish Nutrition v. Sanofi-Aventis (2008), § 19, juez Lewison.

${ }^{53}$ Op. cit., $\S \S 48-52$, juez Lewison, y (2009). Además, en primera instancia se rechazó la pretensión del actor para que la demandada le restituyera las ganancias ilícitas obtenidas por los miembros del cartel por cuanto el tribunal opinó que la indemnización de los perjuicios remediaba adecuadamente al actor: ODUdu y VIRGO (2009), pp. 32-35; SHEEHAN (2009), pp. 222-226.

${ }^{54}$ Albion Water Ltd v. Dwr Cymru Cyfyngedig (2010), §§ 27-38.

${ }^{55}$ V.gr., Díez-Picazo (1999), pp. 44-47; Pantaleón (2000), pp. 167-168; Herrero (2008), p. 113.

${ }^{56}$ Ortíz (2011), pp. 220-233. 
definir autónomamente si admite o no los daños punitivos ${ }^{57}$. La Comisión Europea ha recalcado en el Libro blanco sobre acciones por daños derivados de estas conductas que el fin indemnizatorio de la responsabilidad civil es incompatible con el otorgamiento de cantidades superiores al perjuicio causado por el ilícito ${ }^{58}$. A su vez, la propuesta de directiva no incluye los daños punitivos y reitera que, de acuerdo con el principio de pleno resarcimiento, la responsabilidad civil sirve para restablecer a las víctimas a su estado anterior al hecho dañoso, mediante la indemnización del daño emergente, del lucro cesante y de los intereses ${ }^{59}$.

6. En Chile, los daños punitivos también son descartados con base en el principio de la reparación integral y en la naturaleza resarcitoria de la responsabilidad civil. La indemnización depende de la magnitud del perjuicio y no de la entidad de la conducta nociva. La agravación de la responsabilidad contractual-consagrada en los arts. 1558 del $C C, 1150$ del Code francés y 1107 del $C C$ español, entre otras normas- si bien atiende fines disuasorios y retributivos que se fundan en la gravedad del hecho ${ }^{60}$, es ajena a la responsabilidad aquiliana que surge con independencia de un vínculo jurídico previo ${ }^{61}$. Además, los daños punitivos transgrederían el principio de legalidad, pues se impondrían con el objetivo de castigar conductas que no están tipificadas ni sancionadas en norma legal alguna y vulnerarían el non bis in idem, ya que la infracción sería sancionada dos veces: en sede administrativa y en el litigio civil. Adicionalmente, el juicio civil no brinda garantías tales como la presunción de inocencia que caracterizan al proceso penal. En fin, las víctimas se enriquecerían en forma injusta al recibir más que el daño padecido lo que fomentaría una litigación abusiva ${ }^{62}$. Por consiguiente, sin una reforma legal los daños punitivos no pueden ser aplicados en Chile ${ }^{63}$.

Con todo, la responsabilidad civil satisface funciones disuasivas y sancionadoras en lo atingente al daño patrimonial proveniente de con-

${ }^{57}$ Manfredi v. Lloyd Adriatico Assicurazioni SpA (2006), §§ 83-88 y 93.

${ }^{58} \mathrm{COM}$ (2008), 165 final, p. 3.

${ }^{59} \mathrm{COM}(2013), 404$ final, art. $2^{\circ}$.

${ }^{60}$ Gatica (1959), pp. 117, 309 y ss.; Segura (2005), pp. 641 y 644; Reglero (2002a), p. 65; ROWAN (2012), pp. 202-206.

${ }^{61}$ Alessandri (1943), pp. 15, 47-49, 164, 196 y 552; Gatica (1959), pp. 57-58; Domínguez (2000), pp. 515 y 576 y ss.; Barros (2006), p. 241; Domínguez (2010b), passim; Fueyo con Urbistondo (1953); Servicio Agrícola Ganadero (1993).

${ }^{62}$ Díez-Picazo (1999), pp. 46 y 237; Yzquierdo (2001), p. 52; Segura (2005), p. 652 y ss.; Barros (2006), pp. 304-309.

${ }^{63}$ LARRAín (2009), pp. 707-719. Para este autor las razones esgrimidas en contra de los daños punitivos no son insuperables y, aunque es necesaria una modificación legislativa focalizada (v.gr., "para controlar ciertas conductas en el mercado"), la cuestión esencial es definir qué funciones debe cumplir la responsabilidad civil. 
ductas desleales y anticoncurrenciales. En estas situaciones parece razonable circunscribir la responsabilidad a conductas realizadas con dolo o negligencia grave ${ }^{64}$. La jurisprudencia francesa observa este criterio, por ejemplo, al atribuir responsabilidad por los daños que derivan de los comportamientos desleales ${ }^{65}$. Asimismo, los tribunales chilenos aplican criterios punitivos, aunque como sus pares franceses lo hacen en forma camuflada, v.gr., incrementando la indemnización del daño moral emanado de actuaciones dolosas ${ }^{66}$ y valorando la naturaleza de la conducta del demandado ${ }^{67}$ o la gravedad de su culpa ${ }^{68}$. Lo mismo se aprecia en la jurisprudencia española como da cuenta la doctrina ${ }^{69}$.

Si bien el principio de reparación integral es el núcleo del sistema indemnizatorio nacional ${ }^{70}$, parece del todo sensato distinguir entre las conductas dolosas o gravemente descuidadas y aquéllas sólo negligentes. $\mathrm{El}$ autor de las primeras debiera responder de todos los perjuicios directos, previstos o previsibles e imprevistos o imprevisibles a la época de ejecutar el hecho, mientras que quien comete un ilícito con culpa ordinaria o levísima sólo debiera hacerse cargo de los daños directos previstos o previsibles al tiempo de la ejecución del hecho. Esta interpretación, aunque incorpora un factor retributivo en la responsabilidad aquiliana, no significa implantar los daños punitivos, sino que exige administrar las reglas indemnizatorias discriminando entre diferentes comportamientos. En concreto, tratándose de ilícitos intencionales, como son las conductas anticompetitivas, los perjudicados no recibirán más resarcimiento -pero tampoco menos- que los daños directos previstos e imprevistos. Esta visión no contradice el principio de reparación integral, no pugna con el non bis in idem ni conduce al enriquecimiento injusto de las víctimas ${ }^{71}$. Este

${ }^{64}$ Starck (1947), passim y (1958), p. 505; TunC (1989), pp. 153-155; Starck et. al. (1996), pp. 114 y 150; Carval (1995), p. 145; Vignon-Barrault (2004), pp. 67-68; Viney y Jourdain (2001), p. 4 y ss. y (2006), pp. 563-564.

${ }^{65}$ V.gr.: Cass. Req., 9 de noviembre de 1871, D.P., 1871, 1, p. 211; Cass. com, 18. de abril de 1958, D., 1959, p. 87, n. Fernand Derrida; Cass. com, 21.3.1989, Bull. civ., tome Iv, N 97; Cass. com., 7 de abril de 1998, D., 1999, somm., p. 128, obs. Schmidt-Szalewski; Cass. com, 3 de mayo de 2000, D., 2001, somm., p. 1312, obs. SErra; Cass. com., 12 de mayo de 2004, Gaz. Pal., 2005, somm., p. 571, obs. Didier GuÉvel.

${ }^{66}$ Wessel con Errázuriz (1927); Porzio con Shell (1941); Contra Celedón (1984); Contra Gallardo (1987); Curaqueo con Congregación del Santísimo Redentor (1990); Soto con Banco Santander (2003); Alessandri (1943), pp. 30-31 y 546; Domínguez (1990), passim; Díez (1997), p. 163; Corral (2003), pp. 68-69; Barros (2006), pp. 218-219.

${ }^{67}$ Contra Monroy (1999); Soto con Banco Santander (2003).

${ }^{68}$ Madariaga con Ferrocarriles del Estado (1928); Contra Berenguela (1998).

${ }^{69}$ V.gr. PeÑa (2002), pp. 208-210; De Ángel (2012), p. 83.

${ }^{70}$ Domínguez (2010a), p. 27.

${ }^{71}$ BAnfi (2012b) pp. 3-32. Una defensa de la idea de que el autor del delito civil o del cuasidelito cometido con culpa lata debiera incurrir en una mayor responsabilidad (pero 
argumento permite sortear las dificultades que entrañan los daños punitivos en los sistemas jurídicos tanto continentales como angloamericanos, al mismo tiempo que ayuda a fortalecer el private enforcement doméstico.

\section{LA RESPONSABILIDAD CIVIL COMO MEDIO DE PROTECCIÓN DE LA COMPETENCIA}

1. Cabe preguntarse cuál es el papel que las acciones de responsabilidad civil desempeñan en la defensa de las normas antimonopolios. Para este efecto, es necesario revisar brevemente la situación en Europa y Estados Unidos.

a) En primer término, diversas causas explican por qué hasta ahora las acciones resarcitorias no han hecho un aporte significativo a la protección de la libre competencia en Europa: la dificultad que envuelve la prueba del daño y la causalidad unida a la ausencia de incentivos, tales como: daños triples, la exhibición amplia de documentos y otras pruebas en la fase prejudicial, la exención del pago de costas por quien pierde el pleito y los pactos de cuota litis (contingency fee agreements) ${ }^{72}$; el hecho de que el carácter confrontacional del proceso civil confine la discusión a las alegaciones y probanzas suministradas por las partes ${ }^{73}$; la falta de voluntad de las víctimas para accionar y de los tribunales para aplicar las normas con mayor flexibilidad ${ }^{74}$; etc. Es más, el protagonismo que ostentan las autoridades públicas develaría una mentalidad paternalista, que es la antítesis del vigoroso private enforcement estadounidense bajo el cual los particulares son auténticos "fiscales o procuradores generales" 75 .

El reconocimiento comunitario-europeo del derecho de toda persona a impetrar medidas cautelares y reclamar perjuicios no se condice con la exigua persecución privada de los ilícitos antitrust en el Viejo Continente.

sin que la indemnización supere el daño), con base en el art. 1107 del $C C$ español, en: De Cossío y Corral (1955), pp. 145-146; De Ángel (1988), pp. 264-265.

${ }^{72}$ Wireless Group Plc v. Radio Joint Audience Research Ltd. (2004), § 53, juez Lloyd; Holmes (2004), p. 28; RaYment (2005), p. 149. La regla "el perdedor paga" (the loser-pays rule) puede incentivar o desalentar demandas y transacciones: SALOP and White (1986), pp. 1049-1052. Empero, la litigación puede ser mal utilizada si los actores nunca tienen que pagar los costos (que es la regla norteamericana): SNYDER and KAUPER (1991), p. 596 y ss.; EPSTEIN (2008), p. 884. En Inglaterra, los contingency fee agreements son prohibidos para prevenir litigación de mala fe y que los abogados aconsejen invariablemente ir a juicio: Callery v. Gray (2001). La Courts and Legal Services Act, de 1990, sólo autoriza los conditional fee agreements, esto es, honorarios pagaderos al abogado del vencedor: AnDRews (2007), pp. 1770-1772.

${ }^{73}$ YeUnG (1998), pp. 586 y 608; Jones (1999), pp. 35-36; Jolowicz (2000), pp. 28 y 176-177.

${ }^{74}$ Heinemann (2011), pp. 228-229.

${ }^{75}$ Associated Industries of New York State, Inc. v. Ickes (1943), p. 704, juez Franck. Lever (2001), p. 111; Gerber (2007), pp. 431-451; PAulis (2007), pp. 7-16. 
Por ejemplo, en las últimas cuatro décadas en Inglaterra se han dictado sólo unas pocas sentencias en juicios de responsabilidad civil por estas $\operatorname{conductas}^{76}$. A su vez, la Comisión Europea, consciente de que los entes públicos no pueden investigar toda clase de infracciones, pues sus recursos son limitados, promueve con insistencia la interposición de acciones privadas, en particular las de naturaleza indemnizatoria. La posición oficial de dicho órgano, plasmada en el Libro blanco sobre acciones por daños anticompetitivos ${ }^{77}$ y en la propuesta de directiva que profundiza en el tópico ${ }^{78}$, es que la prevención de conductas anticoncurrenciales es un objetivo público, mientras que la reparación de los daños atañe sólo a sus víctimas ${ }^{79}$. De ahí la proposición de combinar balanceadamente el public enforcementy el private enforcement, por ejemplo, encomendando a las autoridades administrativas el combate de los carteles y reservando a los privados las acciones contra las restricciones verticales ${ }^{80}$. De igual forma, el éxito del private enforcement supone de reglas sustantivas y procesales aplicables a los juicios indemnizatorios, además de la cooperación entre órganos jurisdiccionales y autoridades públicas ${ }^{81}$.

b) En segundo término, los juicios sobre responsabilidad civil suelen seguir a la declaración del ilícito en sede administrativa: son follow-on actions. Generalmente los demandantes se basan en la investigación y en las pruebas 232 reunidas en el proceso conducido por la autoridad del ramo e invocan el efecto de cosa juzgada de la declaración del ilícito anticompetitivo en el litigio civil ulterior $^{82}$. Por consiguiente, el debate queda circunscrito al daño y la causalidad, lo cual reduce el costo e incertidumbre que todo pleito conlleva ${ }^{83}$. El órgano público posee amplias facultades inspectoras, correccionales y de evaluación del costo social engendrado por la conducta antitrust. No obstante, por razones políticas y presupuestarias la persecución pública se concentra en los atentados más graves y este hecho repercute en un

${ }^{76}$ Rodger (2008), pp. 96-116.

${ }^{77} \mathrm{COM}$ (2008), 165 final.

${ }^{78} \mathrm{COM}$ (2013), 404 final.

${ }^{79}$ Wils (2009), pp. 3-26; Whish and Bailey (2012), p. 297.

80 Terhechte (2011), pp. 11-20; Pohlmann (2011), pp. 157-163; Foer and Cuneo (2012), p. 592.

${ }^{81}$ Cengiz (2010), pp. 39-63.

${ }^{82}$ Con arreglo a la sección 58A de la Competition Act, de 1998, la declaración de conducta anticompetitiva produce efecto de cosa juzgada en el juicio indemnizatorio siguiente que se ventile en el CAT: STANTON et al. (2003), pp. 412-414; BEARD (2005), pp. 258263; Möllers and Heinemann (2007), p. 401; Whish (2008), pp. 303-304. Análogamente, en Estados Unidos las sentencias dictadas en investigaciones por ilícitos antitrust son medios de prueba irrefutables en juicios civiles posteriores: sección 5(a), Sherman Act, de 1890.

${ }^{83}$ Lever (2001), p. 109 and ss.; Siragusa and D’Ostuni (2007), pp. 477-485; Komninos (2008), p. 7 y ss.; SMITH et al. (2012), pp. 297-298. 
menor volumen de litigación civil ${ }^{84}$. Por ejemplo, en Inglaterra no se han deducido muchas acciones follow-on, ni siquiera ante el CAT ${ }^{85}$, pese a ser éste un foro más preparado que la High Court ${ }^{86}$ para resolver demandas de daños atendida su composición mixta (juristas, economistas y contadores) y el hecho de que su competencia está restringida a estas materias ${ }^{87}$. Las acciones independientes de toda condena previa (standalone actions) sólo se justificarían tratándose de ilícitos que no revisten interés para la autoridad pública ${ }^{88}$. Pero la presentación de estas demandas autónomas es una estrategia riesgosa, ya que el actor deberá acreditar no sólo el daño y la causalidad sino, también, el ilícito ${ }^{89}$. En Inglaterra las acciones stand-alone deben ser deducidas ante la High Court ${ }^{90}$ la que sólo ocasionalmente las acoje ${ }^{91}$; y si no las rechaza ${ }^{92}$ es porque las partes han celebrado transacciones confidenciales y extrajudiciales, a menudo con

${ }^{84}$ YeUnG (1998), pp. 598-599; Wils (2003), pp. 473-488; WALler (2003), pp. 230-231.

${ }^{85}$ Sección 47A, Competition Act, de 1998. En Healthcare at Home v. Genzyme Ltd (2006) el CAT por primera vez concedió indemnización de perjuicios, pero las partes transigieron. En Enron Coal Services Limited (in liquidation) v. English Welsh \& Scottish Railway Limited (2009 y 2011) se rechazó la demanda de perjuicios por falta de causalidad. En Travel Group PLC (in liquidation) v. Cardiff City Transport Services Limited (2012) se acogió la demanda por lucro cesante y daños punitivos a consecuencia de la práctica predatoria de la demandada. En Albion Water Limited v. Dr Cymru Cyfyngedig (2013) se acogió la demanda de perjuicios derivados de abuso de posición dominante, pero se desestimaron los daños punitivos. Véase WHISH and BAILEY (2012), pp. 317-318.

${ }^{86}$ Este tribunal ordinario de primera instancia también puede conocer de dichas acciones, pero admite que el CAT es un foro técnicamente más adecuado: Claritas (U.K.) Ltd. v. The Post Office (2000); Attheraces Ltd. v. British Horseracing Board Ltd. (2007).

${ }^{87}$ Rodger (2003), p. 113; Brown (2007), pp. 488-493; Clough and Wilson (2007), pp. 308-311; WHISH (2008), p. 300.

${ }^{88}$ Jacobs (1984), pp. 1364-1376; Foer and Cuneo (2012), pp. 596-597.

${ }^{89}$ Rodger (2003), p. 104 y ss.; VAn Gerven (2007), p. 23 y ss.

${ }^{90} \mathrm{El} \mathrm{CAT}$ es incompetente para conocer de tales acciones: secciones $47 \mathrm{~A}, 58 \mathrm{~A}$ y 60 , Competition Act, de 1998.

${ }^{91}$ V.gr., Inntrepreneur Estates Ltd. v. Mason (1993) y Hendry v. World Professional Billiards and Snooker Assoc. Ltd. (2001), §§ 112-113. En Attheraces v. British Horseracing Board (2007), la High Court condenó a la demandada por abuso de posición dominante al amenazar a la actora con no venderle información sobre carreras de caballos auspiciadas por la primera -administradora y reguladora de la materia en el Reino Unido-mediante la imposición de precios excesivos y discriminatorios. Sin embargo, el libelo fue rechazado en segunda instancia, estimándose que la imposición de un precio por sobre el costo no configuraba un abuso. Además, la Corte de Apelaciones estableció que el art. 102 TFUE tiene por propósito proteger a los consumidores (los apostadores finales) y no a los competidores, cuyo era el caso de la demandante.

${ }^{92}$ V.gr., Claritas (UK) Ltd v. Post Office (2001); Crehan v. Inntrepreneur Pub Co (CPC) (2006); Bookmakers Afternoon Greyhound Services Ltd $v$. Amalgamated Racing $\operatorname{Ltd}(2009)$. 
ingentes indemnizaciones de por medio ${ }^{93}$. Por ejemplo, en Arkin v. Borchard Lines Ltd (2003) la High Court desestimó la acción indemnizatoria porque no se probó la intención del demandado de expulsar al actor del mercado ni que éste hubiese mitigado sus pérdidas, sea abandonando oportunamente el mercado, sea solicitando medidas cautelares ${ }^{94}$. Pero las acciones stand-alone han prestado un servicio como defensas y como demandas reconvencionales de nulidad contra acciones de cumplimiento forzado de contratos anticompetitivos ${ }^{95}$. Asimismo, la High Court puede suspender el procedimiento civil hasta que la investigación de la infracción concluya con una sentencia condenatoria que tendrá efecto de cosa juzgada en aquél ${ }^{96}$. En fin, las acciones stand-alone de naturaleza cautelar permiten, cumpliéndose ciertos requisitos ${ }^{97}$, detener la perpetración de las conductas anticompetitivas ${ }^{98}$.

c) Frente a la escasa litigiosidad civil por ilícitos antitrust en Europa, resulta sorprendente que algunos académicos propongan la implementación de mecanismos procesales y sustantivos para evitar que los privados interpongan denuncias o demandas indemnizatorias frívolas para conseguir o consolidar posiciones monopólicas ${ }^{99}$. En este sentido, se tienen en cuenta estudios realizados en Estados Unidos que niegan la legitimación activa a quienes pretenden quejarse de las fusiones de sus rivales y argumentan

${ }^{93}$ Como la transacción entre productores farmacéuticos y el Ministerio de Salud inglés, según lo informado por la prensa el año 2005, anunciándose que Ranbaxy (UK) Ltd. pagó $£ 4.500 .000$ y British Airways v. Virgin Atlantic que fue transado en $£ 73.500 .000$ : WHISH y BAILEY (2012), pp. 315-316 y 727.

${ }^{94}$ Milutinovic (2007), pp. 727-757.

${ }^{95}$ En cambio, quien acciona de daños estando pendiente la investigación pública de ilícito anticompetitivo no puede intervenir ni acceder a las pruebas allí reunidas: LEver (2001), p. 113 y ss.; NAZZINI (2004), pp. 79-85; MonTi (2007), p. 434. La prohibición contra la exhibición se basa en la presunción de inocencia y en el derecho a no autoincriminarse: Rio Tinto Zinc Corp. v. Westinghouse (1977). Pero el CAT puede ordenar la revelación de documentos pertinentes a la disputa tras evaluar los intereses legítimos de individuos, empresas y del público: Claymore Dairies Ltd. v. OFT (2004).

${ }^{96}$ Möllers and Heinemann (2007), pp. 403, 458 y ss.; Whish (2008), pp. 303-304.

${ }^{97}$ Deberá probarse la existencia de un asunto grave que resolver; rendirse fianza de resultas; demostrarse que esa medida no causará más daño que el que se intenta evitar ni mayor injusticia que si la solicitud fuese denegada; y el tribunal deberá concluir que la indemnización no es un remedio adecuado: American Cyanamid Co. v. Ethicon Ltd. (1975); AAH Pharmaceuticals Ltd v. Pfizer Ltd (2007), §§ 49-57. Véase Jacobs (1983), pp. 353-357; Brealey and Hoskins (1998), p. 149 y ss.; ANdrews (2007), p. 1725; Whish and BAILEY (2012), p. 310.

${ }^{98}$ La High Court tiene la facultad privativa para decretarlas: Garden Cottage Foods Ltd. v. Milk Marketing Board (1983), p. 151, juez Wilberforce; Holleran v. Daniel Thwaites Plc (1988), § 51, juez Gibson; STEInER (1987), pp. 102-122.

${ }_{99}$ YeUnG (1998), p. 592; Jones (1999), p. 181. 
que el mero hecho de presentar la denuncia constituiría una presunción de que la fusión tiene efectos procompetitivos ${ }^{100}$.

2. Por su parte, la experiencia estadounidense muestra que las acciones privadas, incluyendo las indemnizatorias, son utilizadas frecuentemente como un negocio o un modo de intimidar a los competidores. La existencia de treble damages y la aversión al riesgo de ser condenados a pagarlos con frecuencia compelen a los demandados a suscribir transacciones a cambio de permitir a los actores perseverar en sus prácticas anticompetitivas ${ }^{101}$. El abuso de la litigación civil redunda en procesos dilatados, costosos y complejos en lo referente a la medición, prueba y distribución de los daños; acarrea pagos múltiples diluidos entre numerosos actores; e incide en la dictación de fallos erróneos e inconsistentes. Con el objetivo de prevenir o disminuir el abuso del private enforcement, la jurisprudencia estadounidense evalúa el mérito de las acciones, considera el posible impacto pro competitivo de las conductas bajo escrutinio y limita la legitimación activa en la etapa inicial del juicio ${ }^{102}$.

a) En primer lugar, el demandante debe acreditar el antitrust injury, esto es:

i) que sufrió un daño o amenaza de daño como consecuencia directa del ilícito anticompetitivo;

ii) que él pertenece a la clase de personas o sector económico afectado por la infracción que la ley busca evitar y

iii) que el daño reclamado es del mismo tipo que aquél que las normas pretenden prevenir ${ }^{103}$.

El antitrust injury permite verificar la existencia de una conexión suficientemente cercana entre el daño y los fines de las leyes antimonopolios. En Brunswick Corp. v. Pueblo Bowl-O-Mat, Inc. (1977) el actor operaba establecimientos de bowling que competían con otros que habrían quebrado si no hubiesen sido adquiridos por el demandado. Esta compra impidió al actor incrementar sus utilidades. Los jueces del fondo consideraron que la adquisición era ilícita, ya que deterioraba el mercado del bowling. En tanto, la CS concluyó que el daño alegado emanaba de la competencia legítima emprendida por los negocios que el demandado había comprado y mantenido ${ }^{104}$. Este fallo fue extendido a las acciones cautelares. En Cargill, Inc. v. Monfort of Colorado, Inc. (1986), el actor pidió que se prohibiera la fusión de dos adversarios. Los tribunales de la instancia estimaron

\footnotetext{
${ }^{100}$ Baumol y Ordover (1985), pp. 247-265.

${ }^{101}$ Austin (1978), pp. 1353-1374; Snyder and Kauper (1991), p. 551 y ss.

${ }^{102}$ Page (1985), pp. 1445-1512; Areeda and Kaplow (1997), p. 76 y ss.; Jones (1999),

p. 177; BEARD (2005), pp. 272-273; MonTI (2007), p. 431 y ss.

${ }^{103}$ Brunswick Corp. v. Pueblo Bowl-O-Mat, Inc. (1977).

${ }^{104}$ Areeda and Kaplow (1997), pp. 77-86; Jones (1999), p. 153 y ss.
} 
que la fusión era ilícita porque acentuaba la concentración del mercado y conducía a la colusión entre firmas oligopólicas. Pero la CS rechazó la demanda, pues en su concepto la fusión aumentaba la competencia y beneficiaba al actor con un alza de los precios. Una medida cautelar sólo se justificaría si la fusión representara un riesgo evidente de predación. En Atlantic Richfield Co. v. USA Petroleum Co. (1990), otro importante caso, un refinador de petróleo y sus distribuidores habían pactado precios máximos de reventa del crudo. Ciertos distribuidores que vendían marcas rivales demandaron al refinador la indemnización del lucro cesante al no poder cobrar los precios de reventa que deseaban. La CS resolvió que esta pérdida no encuadraba en el tipo de daño que la norma pretende prevenir sino que provenía de una competencia legítima, toda vez que los precios de reventa no eran tan bajos como para constituir precios predatorios. La corte aclaró que la ilicitud del acuerdo de fijación de precios de reventa no reside en el daño que pueda ocasionar a los competidores sino en el atropello de la libertad de los distribuidores para elegir la combinación adecuada de precios y servicios, privando a los consumidores de los servicios que esperan recibir. El daño a los adversarios sólo existiría si se tratara de precios predatorios que excluyen del mercado a distribuidores eficientes de otras marcas ${ }^{105}$.

236 b) En segundo lugar, desde el caso Illinois Brick Co. v. Illinois (1977) la jurisprudencia federal estadounidense limita la legitimación activa a los competidores y a los compradores directos de bienes o servicios del infractor, negándosela a los compradores indirectos, quienes son comúnmente consumidores finales ${ }^{106}$. Aunque en el ámbito estatal puede conferirse y se ha concedido legitimación a los compradores indirectos ${ }^{107}$, el caso Illinois es un precedente junto a Hanover Shoe, Inc. v. United Shoe Machinery Corp (1968). En Hanover la Corte Suprema rechazó la defensa del passing-on, vale decir, de la indemnización de perjuicios reclamada por el comprador directo no es posible rebajar los precios excesivos pagados por éste al infractor y traspasados a los compradores indirectos:

"cualquiera sea el precio en que el comprador venda, el precio que él paga al vendedor sigue siendo ilegalmente alto y sus ganancias serían mayores si sus costos fuesen inferiores" ${ }^{108}$.

${ }^{105}$ Areeda et. al. (2004), pp. 68-69.

${ }^{106}$ Las acciones de las víctimas directas no están sujetas a requisitos adicionales: Radovich v. National Football League (1957), p. 454.

${ }^{107}$ California v. ARC America Corp (1989).

${ }^{108}$ Hanover Shoe, Inc. v. United Shoe Machinery Corp (1968), p. 489. 
Esto conduce al absurdo de que el comprador directo puede demandar daños que no sufrió mientras que el comprador indirecto no puede reclamar perjuicios que sí soportó. La jurisprudencia niega legitimación a toda clase de víctimas indirectas, incluyendo accionistas y acreedores de la empresa afectada por el ilícito ${ }^{109}$; salvo algunas excepciones, en particular, cuando el comprador directo no tiene una posibilidad real de demandar ${ }^{110}$.

c) Esta tendencia jurisprudencial se basa en diversas consideraciones: los costos de litigar exceden la indemnización que cada comprador indirecto podría percibir, además de la enredada cuantificación del daño ${ }^{111}$, mientras que estos costos decaerían y el nivel de prevención aumentaría si la legitimación es restringida ${ }^{112}$; los compradores directos reducirían los mayores costos ocasionados por el ilícito y, por ende, los compradores indirectos pagarían menores precios ${ }^{113}$; las víctimas directas tendrían mayor chance de obtener un resarcimiento debido a su relación permanente y cercana con el infractor ${ }^{14}$; el otorgamiento de acción a los compradores indirectos propendería a una excesiva litigación y acrecentaría el riesgo de dobles indemnizaciones con la dificultad adicional de repartir estas sumas entre infinidad de demandantes. La restricción de legitimación evitaría tramitar procesos contra ilícitos socialmente inocuos, por cuanto toda demanda deducida por una persona vinculada de forma remota a la infracción sería desestimada al comienzo del pleito ${ }^{115}$. En fin, si los compradores indirectos gozaran de legitimación activa y los infractores pudiesen oponer el passing-on, los únicos sujetos en situación de probar la responsabilidad -los compradores directos- no tendrían razón para demandar y esto debilitaría el grado de disuasión de estos ilícitos ${ }^{116}$.

d) En contra, se asevera que al negarse legitimación a los compradores indirectos el infractor puede conservar sus ganancias ilícitas lo que deteriora la eficacia preventiva de las acciones indemnizatorias ${ }^{117}$. Dicha tendencia evidenciaría la falta de voluntad de los jueces a tramitar pleitos cuya prueba es enrevesada ${ }^{118}$. Además, es dudoso si la restricción de legitimación previene los ilícitos antitrust habida cuenta que los compradores

${ }^{109}$ Kreager v. GE (1974).

${ }^{110}$ Freeman v. San Diego Asśn of Realtors (2003).

${ }^{111}$ Möllers and Heinemann (2007), pp. 644-645; Epstein (2008), p. 1255.

${ }^{112}$ Hylton (2003), p. 63.

${ }^{113}$ Landes and Posner (1979), pp. 602-635.

114 Associated General Contractors of California v. California State Council of Carpenters (1983); PAGE (1985), passim.

${ }^{115}$ Areeda et al. (2004), pp. 60-61.

${ }^{116}$ BeARd (2005), p. 274 y ss.

${ }^{117}$ Areeda et al. (2004), pp. 62-63.

${ }^{118}$ Berger and Bernstein (1977), pp. 809-883. 
directos no tienen interés en accionar contra los infractores pues han transferido a los compradores indirectos el precio excesivo pagado a los primeros $^{119}$. En contraste, en Europa toda persona puede demandar la reparación del daño emanado de atentados a la libre competencia ${ }^{120}$ y se valora la defensa passing-on como forma de impedir que los compradores directos se enriquezcan injustamente, reclamando daños que trasladaron a los compradores indirectos ${ }^{121}$. Sin embargo, la defensa passing-on tropieza con la embrollada avaluación del daño ${ }^{122}$. Una posible salida consiste en autorizar a los compradores indirectos para que intervengan en los juicios indemnizatorios iniciados por los compradores directos y obtengan el reembolso de los sobreprecios pagados ${ }^{123}$. Con todo, el resarcimiento de los compradores indirectos es prácticamente imposible en ausencia de acciones de clase. En efecto, el daño que cada comprador indirecto padece es demasiado ínfimo y su prueba demasiado intrincada como para alegarlo en forma individual ${ }^{124}$. De ahí que en jurisdicciones como la británica, que no proporcionan acciones de clase en este contexto, la legitimación activa quede confinada a los compradores directos ${ }^{125}$.

3. Tal vez uno de los aspectos más polémicos es si el fortalecimiento del private enforcement (y de las acciones de daños en particular) contribuye a prevenir los actos anticoncurrenciales. Si bien el nivel óptimo de prevención es una incógnita, el incremento de las multas y el uso de diversas acciones privadas no han logrado disuadir la comisión de estos ilícitos, sobre todo los carteles. Ante esta realidad se insiste en robustecer la prosecución pública y las acciones privadas como su natural complemento ${ }^{126}$. Pero un sector de la doctrina anglosajona tiene serias aprensiones sobre la eficacia disuasiva de las acciones privadas, en parte porque las víctimas son reacias a embarcarse en litigios cuyo desenlace es impredecible ${ }^{127}$.

${ }^{119}$ FOER (2011), pp. 208-209.

${ }^{120}$ Courage Ltd. v. Crehan (2001); Manfredi v. Lloyd Adriatico Assicurazioni SpA (2006).

${ }^{121}$ Milutinovic (2007). La reciente propuesta de directiva [COM(2013) 404 final] reconoce a toda persona natural o jurídica -esté o no contractualmente vinculada con el infractor y se haya establecido o no el ilícito- el derecho a la reparación del daño emergente, lucro cesante e intereses (devengados entre la fecha del daño y la del pago efectivo de la indemnización) emanados de la conducta antitrust. Asimismo, ella concede la defensa del passing-on para prevenir el enriquecimiento injusto del comprador directo que traspasó los costos excesivos a los compradores indirectos. El demandado (infractor) deberá probar dicho traspaso de costos.

${ }^{122}$ Como fue sugerido en Kleinwort Benson Ltd. v. Birmingham CC (1996) y resuelto en Marks \& Spencer Plc v. Commissioners of Customs and Excise (1999).

${ }^{123}$ Petrucci (2008), pp. 96-116.

${ }^{124}$ Roin and Monsour (2006), pp. 973-981.

${ }^{125}$ BCL Old v. Aventis (2005).

${ }^{126}$ Foer (2011), p. 208.

${ }^{127}$ Rodger (2008), pp. 96-116. 
Adicionalmente, el riesgo de incurrir en responsabilidad infraccional afecta los programas de delación compensada y, en consecuencia, a la prevención y sanción de los carteles. En este sentido, se sugiere que las acciones privadas sean utilizadas de modo exclusivo contra conductas que lesionan a un número acotado de personas, sin que obstruyan formas lícitas de competencia ${ }^{128}$, y que los ilícitos más graves sean enfrentados a través de medidas cautelares y no de acciones resarcitorias ${ }^{129}$. En Estados Unidos, principalmente Robert Lande y Joshua Davis califican el private enforcement como un mecanismo exitoso en la prevención de comportamientos antitrust, en el resarcimiento de víctimas y en la modificación de conductas en orden a su mayor eficiencia y competitividad. Se trataría de un paradigma para toda nación que contemple un modelo privado de protección de la libre competencia ${ }^{130}$. Por el contrario, para Daniel Crane ese sistema ha fracasado en la prevención y reparación del costo social (deadweight loss) representado por la privación de bienes o servicios deseados a raíz del precio excesivo impuesto por las conductas anticoncurrenciales, obligando a los consumidores a adquirir sustitutos de inferior calidad. Tampoco ha prevenido ni reparado el "daño dinámico" o indisponibilidad de productos innovadores que el público podría adquirir en ausencia del ilícito anticompetitivo. Es más, los compradores directos -únicos sujetos legitimados activamente- no tendrían incentivo para demandar, pues trasladan los mayores costos a los compradores indirectos, mientras que éstos carecen de legitimación y deben cargar con los costos procesales los que a menudo superan la indemnización que podrían obtener mediante acciones de clase $^{131}$ :

"la acción de clase, salvo en el caso de grandes compradores institucionales, es un engaño. No existe un método factible para localizar y reembolsar al consumidor que varios años atrás pudo haber pagado demasiado por un dentífrico" ${ }^{132}$.

De esta forma, Daniel Crane afirma que si el private enforcement no ha sido exitoso en Estados Unidos pese a contar con diversos incentivos, con mayor razón fracasará en sistemas jurídicos que no contemplan dichos estímulos ${ }^{133}$. Las críticas formuladas por Daniel Crane no son extensibles a los competidores, pues éstos gozan de legitimación activa. Sin embargo,

\footnotetext{
${ }^{128}$ EGER and WeISE (2011), pp. 31-46.

${ }^{129}$ ReICH (2005), pp. 35-65.

${ }^{130}$ Lande and Davis (2008), pp. 879-918; LANDE (2012), pp. 3-11.

${ }^{131}$ Crane (2011), pp. 163-168 y 174.

${ }^{132}$ Posner (1969), p. 1590.

${ }^{133}$ Crane (2011), pp. 182-187 y 209.
} 
dicho autor cuestiona la indemnización en favor de los rivales no sólo porque éstos suelen abusar de las acciones con fines anticompetitivos sino que, en especial, porque rara vez son perjudicados; y cuando un rival es dañado, ello normalmente obedece a ilícitos que son inocuos tanto para los consumidores como para el funcionamiento del mercado ${ }^{134}$. En definitiva, la eficacia de las acciones de responsabilidad civil es dudosa respecto de las infracciones socialmente más nocivas -esto es, los acuerdos colusorios- y como medio de protección de los consumidores.

4. Los juicios por ilícitos antitrust envuelven complicadas cuestiones fácticas, técnicas y políticas. Deben compararse los efectos pro y anticompetitivos del hecho y balancearse la certeza jurídica con la eficiencia económica ${ }^{135}$.

a) Fundamentalmente el actor civil debe acreditar un daño específico sufrido como consecuencia directa y necesaria de la infracción anticoncurrencial. El demandante tendrá que contestar una pregunta hipotética, a saber: que, en ausencia del ilícito, no habría experimentado una pérdida o habría percibido una ganancia ${ }^{136}$. El daño puede consistir en la diferencia entre el precio excesivo pagado por la víctima y el precio de mercado que, en otro caso, ésta habría pagado. Esto implica examinar la variación de las circunstancias previas, concomitantes y posteriores al ilícito ${ }^{137}$. La prueba 240 del daño exige comparar las ganancias percibidas por el actor producto de la conducta anticompetitiva con las que obtuvo antes o después de ésta o con las utilidades obtenidas por rivales en negocios relacionados que no han sido afectados por el acto anticoncurrencial. Al respecto, es usual que se formulen severos reparos a la posibilidad de cotejar distintos períodos, empresas y mercados. Para acreditar estas ganancias eventuales, normalmente deberá recurrirse a informes de peritos y testimonios de expertos que expliquen el método utilizado y logren convencer al juez de que la estimación del daño se sustenta en los hechos de la causa y no en meras conjeturas ${ }^{138}$. Sólo esta clase de evidencia permitirá al sentenciador construir presunciones judiciales ${ }^{139}$. Además, habrá que cuantificar dicha utilidad $^{140}$ y precisar desde cuándo se computarán los perjuicios ${ }^{141}$.

${ }^{134}$ Crane (2011), pp. 171-172.

${ }^{135}$ JaCOBs (1984), pp. 1368 and 1374; YeUnG (1998), pp. 585-586.

${ }^{136}$ Shavell (1987), p. 138.

${ }^{137}$ Wall Prods. Co. v. National Gypsum (1973).

${ }^{138}$ Bigelow v. RKO Radio Pictures (1946), pp. 264-265, juez Stone.

${ }^{139}$ Areeda et al. (2004), pp. 58-59.

${ }^{140}$ Rodger (2003), p. 109 y ss.; Beard (2005), pp. 280-281; Van Gerven (2007), p. 31 y ss.; Möllers and Heinemann (2007), p. 399.

${ }^{141}$ Whish and Bailey (2012) p. 311. 
b) A su vez, la causalidad es crucial para imputar responsabilidad y determinar si el actor tiene legitimación activa. De ahí que la jurisprudencia estadounidense revise este elemento como requisito de admisibilidad del libelo. Los tribunales estadounidenses analizan con rigurosidad la prueba de la causalidad y del daño. Pero para evitar que los infractores eludan su responsabilidad, no exigen que se acredite el monto del daño con exactitud sino que es suficiente una estimación razonable que permita contrastar el perjuicio real con la utilidad que el actor habría obtenido en ausencia del ilícito. En este sentido, una famosa sentencia declaró:

"Las concepciones más elementales de justicia y política pública requieren que el infractor soporte el riesgo de incertidumbre que ha creado con su propio ilícito" 142 .

\section{LA SITUACIÓN CHILENA}

1. De acuerdo con la evidencia empírica existente, más del $70 \%$ de los casos resueltos por el TDLC entre los años 2004 y 2012 fueron iniciados mediante denuncias de particulares. Sin embargo, la probabilidad de que estos últimos obtuvieran una sentencia favorable fue sólo de un $16 \% \mathrm{y}$, en los hechos, únicamente en el $27 \%$ de los juicios que concluyeron por sentencia los denunciantes lograron que se sancionara a los infractores. Por el contrario, en los litigios iniciados por la FNE, o en los que ésta intervino, la probabilidad de obtener una condena se elevó al 56\%. Además, en el 64\% de los pleitos en que participó la FNE y que terminaron por sentencia, dicho órgano público logró una condena ${ }^{143}$.

2. Bajo el imperio de la antigua Comisión Resolutiva sólo se ventiló un litigio de responsabilidad civil emanado de atentados a la libre competencia, a saber: el juicio entre Aerovías DAP (y sus socios personas naturales, de apellido Pivcevic) y LAN Chile, LADECO y National Airlines. Las

${ }^{142}$ Bigelow v. RKO Radio Pictures (1946), pp. 264-265, juez Stone. En forma similar, se ha resuelto: "existe una distinción clara entre la medida de prueba necesaria para establecer el hecho de que el demandante ha sufrido algún daño y la medida de prueba necesaria para permitir al jurado fijar el monto": Story Parchment Co. v. Paterson Parchment Paper Co. (1931), p. 562, juez Sutherland. En el mismo sentido: Zenith Radio Corporation v. Hazeltine Research, Inc. (1969), pp. 123-124, juez White (sosteniéndose que no es necesario que el daño tenga por única la supuesta infracción); J. Truett Payne Company, Inc. v. Chrysler Motors Corporation (1981), pp. 565-567, juez Rehnquist (fallándose que el daño no puede ser presumido del solo hecho de que el demandado cobre precios muy inferiores a los del rival: op. cit., pp. 561-562).

${ }^{143}$ GonZÁlez y Micco (2013), pp. 13 y 25. 
tres demandadas fueron condenadas a indemnizar solidariamente los perjuicios patrimoniales que su práctica predatoria causó a los actores. Ésta fue la primera oportunidad en que la CS se pronunció sobre la materia ${ }^{144}$.

3. Por su parte, desde la instalación del TDLC y bajo la vigencia del art. 30 del DL No 211, los juicios indemnizatorios resueltos por sentencia firme o transigidos se reducen a cuatro: Sound Colour con United International Pictures Chile (2009), única demanda stand-alone que se ha interpuesto en Chile y que fue rechazada por falta de prueba del ilícito anticompetitivo, ya que el TDLC había absuelto previamente a la demandada ${ }^{145}$; Cementa S.A. con James Hardie Fibrocementos Ltda. (2009), demanda de perjuicios fundada en precios predatorios y que fue acogida en primera instancia para luego ser transigida estando pendiente recurso de apelación; Producción Química y Electrónica Quimel S.A. con James Hardie Fibrocementos Ltda. (2009), demanda de perjuicios similar a la anterior, rechazada en primera instancia por ausencia de causalidad y transigida encontrándose pendiente la apelación y Philip Morris con Compañía Chilena de Tabacos (2013), demanda acogida parcialmente, siendo ésta la segunda ocasión en que la CS falla un juicio de esta naturaleza (pero la primera bajo la vigencia del art. 30 del DL No 211) ${ }^{146}$.

4. Por último, en el caso SERNAC con Farmacias Cruz Verde y Otras 242 (2013) por primera vez se reclama la indemnización de los perjuicios en representación del interés colectivo y difuso de los consumidores, en la especie afectados por la colusión de tres empresas farmacéuticas. La acción fue declarada inadmisible en primera instancia, en atención a los siguientes argumentos: el procedimiento sumario previsto en el art. 30 del DL N 211 descarta la posibilidad de aplicar aquél regulado en el art. 50 y siguientes de la ley $\mathrm{N}^{\circ} 19.496$; el SERNAC carece de legitimación activa, ya que no fue parte del proceso ante el TDLC que condenó a dos de las aludidas cadenas farmacéuticas; la demanda debió ser basada en una infracción a la ley $\mathrm{N}^{\mathrm{o}} 19.496$ y no en un ilícito anticompetititivo; y no existe certeza sobre los consumidores que resultarían beneficiados con dicha acción. Aunque a la fecha de este trabajo la aludida sentencia se

${ }^{144}$ Pivcevic y otros con LAN Chile (2006). La sociedad demandante solicitó \$1.016.817.813 a título de daño emergente, $\$ 2.781 .788 .387$ por el lucro cesante y $\$ 1.800 .000 .000$ como daño moral. En definitiva, se rechazó el daño moral impetrado, se dio lugar al daño emergente y se otorgó el lucro cesante, pero acotado a un período de dos meses y medio.

${ }^{145}$ UIP Chile Ltda. y Andes Films S.A. contra dictamen No 1.277 Comisión Preventiva Central (2005).

${ }^{146}$ La actora solicitó aproximadamente US\$160.000.000 entre daño emergente, lucro cesante y daño moral. La demandada fue condenada a pagar alrededor de US\$2.100.000, acogiéndose así una parte menor de la solicitud de lucro cesante mientras que las otras partidas reclamadas fueron desestimadas. 
encuentra con recurso de apelación pendiente, para disipar toda duda sería conveniente una reforma legislativa que contemplara en forma expresa acciones de clase en este ámbito ${ }^{147}$.

5. Los datos referidos sugieren que, tratándose de denuncias privadas ante el TDLC, el private enforcement ha sido abundante, aunque notoriamente menos eficaz que el public enforcement, en términos de condenas por ilícitos anticoncurrenciales. A su vez, los juicios de responsabilidad civil por ilícitos anticompetitivos entre contendores que han culminado por sentencia o transacción son muy escasos y medianamente exitosos: tres de las cinco demandas fueron acogidas (pero una fue transada) y las indemnizaciones otorgadas han sido bastante más reducidas que las sumas reclamadas.

6. Si bien es muy temprano para extraer conclusiones e, incluso, para hacer diagnósticos, a una década de vigencia del art. 30 del DL No 211 la litigiosidad en responsabilidad civil por ilícitos antitrust es todavía insignificante. Hasta ahora, la contribución que este mecanismo ha hecho a la defensa de la libre concurrencia es discreta en volumen y efectividad. Por último, aún está por verse la importancia resarcitoria y disuasoria que adquirirán las acciones indemnizatorias que los consumidores lesionados por conductas anticompetitivas puedan interponer, aunque un reconocimiento explícito de acciones de clase en el DL No 211 podría despejar las incertidumbres que ya esboza la embrionaria jurisprudencia civil.

7. Uno de los factores que puede explicar el lánguido desarrollo de las acciones de daños por ilícitos anticompetitivos entre competidores en Chile es, como se aprecia en la inicipiente jurisprudencia aludida, la complejidad intrínseca a la prueba del perjuicio resarcible y de la relación causal. Quien es lastimado por su adversario debe acreditar un perjuicio específico autónomo y diferente del daño anticompetitivo ${ }^{148}$ que la conducta ha producido en el mercado y en el conjunto de consumidores. Asimismo, como aparece de la información empírica disponible, el private

${ }^{147}$ El 11 de junio de 2013 ingresó al Congreso Nacional el proyecto de ley que permite reclamar en forma colectiva indemnización de perjuicios por sentencia dictada por el TDLC (Boletín N 8979-03). El proyecto propone agregar en el art. 30 del DL No 211 este inciso: "En los casos de infracciones en la presente ley, que afecten el interés colectivo o difuso de los consumidores en los términos prescritos en el art. 50 de la ley 19.496, los legitimados activos señalados en el art. 51 de la misma norma, podrán reclamar la indemnización de los perjuicios mediante el procedimiento especial establecido en su párrafo 2 del título IV". En: www.senado.cl/appsenado/templates/tramitacion/index. php. [consultado el 12 de octubre de 2013].

${ }^{148}$ Como sugiere Araya (2005), p. 26 y ss., el daño anticompetitivo puede ser una base de cálculo del daño indemnizable en sede civil. Sin embargo, este autor hace la prevención de que las conductas predatorias no causan un daño anticompetitivo y, por ende, el perjuicio indemnizable debe ser probado ex nihilo. 
enforcement ante el TDLC comúnmente ha sido infructuoso lo que clausura la posibilidad de demandar la responsabilidad civil.

\section{Conclusiones}

1. La experiencia foránea, en particular la estadounidense, muestra que la responsabilidad civil hace una contribución acotada a la prevención y sanción de los atentados a la libre competencia, en espeial de los ilícitos más graves, como son los carteles. En efecto, este instituto jurídico privado cumple una función emintemente reparadora del daño que las infracciones anticompetitivas infligen a agentes económicos individuales, como los rivales, y sólo en forma colateral e indirecta puede ayudar a disuadir comportamientos que irrogan un daño anticompetitivo.

2. La evidencia empírica disponible en Chile indica que el private enforcement en forma de denuncias o demandas privadas ante el TDLC ha sido abundante, aunque ineficaz en comparación al public enforcement encabezado por la FNE. Por su parte, el private enforcement consistente en acciones indemnizatorias por ilícitos anticoncurrenciales entre adversarios comerciales ha sido exiguo en volumen y efectividad.

3. El beneficio que los demandantes, sobre todo los competidores, pueden conseguir de una exitosa investigación de comportamientos anticoncurrenciales en principio excede el aporte que a su turno la responsabilidad civil puede hacer, en términos disuasorios, al Derecho de la Competencia. En efecto, las acciones de responsabilidad civil se basan en la declaración de conducta antitrust que necesariamente precede al pleito indemnizatorio. Asimismo, como ocurre en Europa, el sistema jurídico chileno carece de incentivos procesales y sustantivos como aquéllos que definen el poderoso private enforcement estadounidense.

4. Con todo, existen legítimas aprensiones de que el paradigma estadounidense realmente proteja a los consumidores frente a los ilícitos más graves, como son los acuerdos colusorios. En cambio, las acciones privadas, incluyendo las de carácter resarcitorio, han sido un importante mecanismo para resguardar los intereses patrimoniales de agentes económicos afectados por conductas antitrust perpetradas por sus competidores, especialmente abusos de posición dominante y prácticas predatorias. En este sentido, y no obstante la ausencia de incentivos en nuestro Derecho, la todavía reducida litigación civil patria permite vislumbrar un 
aumento paulatino de los juicios de responsabilidad civil por comportamientos anticoncurrenciales entre adversarios.

\section{Bibliografía CitADA}

Alessandri Rodríguez, Arturo (1943). De la responsabilidad extracontractual en el Derecho Civil chileno. Santiago: Imprenta Universitaria.

Andreangeli, Arianna (2004). "Courage Ltd v. Crehan and the enforcement of article 81 EC before the national courts". European Competition Law Reviere. vol. 25. London.

Andrews, Neil (2007). "Civil procedure”, in Andrew Burrows (ed.), English private law. $2^{\text {nd }}$ ed. Oxford: OUP.

Araya Jasma, Fernando (2005). "Daño anticompetitivo y daño indemnizable: un ensayo de confrontación". Revista Chilena de Derecho Privado. $\mathrm{N}^{\circ} 4$. Santiago.

Areeda, Phillip and KaPLow, Louis (1997). Antitrust analysis: problems, text, cases. $5^{\text {th }}$ ed. New York: Aspen Law \& Business.

Areeda, Phillip, Kaplow, Louis and Edun, Aaron (2004). Antitrust analysis. Problems, text, and cases. $6^{\text {th }}$ ed. New York: Aspen Publishers.

Austin, Arthur (1978). "Negative effects of treble damage actions: reflections on the new antitrust strategy". Duke Law Journal. Durham.

BANFi del Río, Cristián. (2012a). "Reflexiones acerca del daño puramente patrimonial”, en Fabián Elorriaga De Bonis (coord.), Estudios de Derecho Civil VII. Santiago: Editorial LegalPublishing-Thomson Reuters.

Banfi Del Río, Cristián. (2012b). "Por una reparación integral del daño extracontractual limitada a los hechos dolosos o gravemente negligentes". Ius et Praxis. año $18, \mathrm{~N}^{\circ}$ 2. Talca.

Barros Bourie, Enrique (2006). Tratado de responsabilidad extracontractual. Santiago: Editorial Jurídica de Chile.

Baumol, William and Ordover, Janusz (1985). "Use of antitrust to subvert competition antitrust and economic efficiency". Journal of Law \& Economics. vol. 28. Chicago.

BEARD, Daniel (2005). "Damages in competition law litigation", in Tim WARD and Kassie Sмiтн (eds.), Competition litigation in the UK. London: Sweet \& Maxwell.

BeCCARIa, Cesare (1996). Of crimes and punishments. (Trad.) Jane Grigson. New York: Marsilio Publishers.

BECKER, Gary (1968). "Crime and punishment: an economic approach". Journal of Political Economy. vol. 76, Chicago.

Bentham, Jeremy (1996). An introduction to the principles of morals and legislation (an authoritative edition by J.H. Burns and H.L.A. Hart). Oxford: Clarendon Press. 
Berger, Daniel and Bernstein, Roger (1977). "An analytical framework for antitrust standing". Yale Law Journal. vol. 86. New Haven.

Brealey, Mark and Hoskins, Mark (1998). Remedies in EC law: law and practice in the English and EC courts. $2^{\text {nd }}$ ed. London: Sweet \& Maxwell.

Breit, William and ElzingA, Kenneth (1974). "Antitrust enforcement and economic efficiency: the uneasy case for treble damages". Journal of Law and Economics. vol. 17. Chicago.

Brown, Christopher (2007). "Section 16 Enterprise Act 2002 - Time for activation?". European Competition Law Review. vol. 28. London.

Buxbaum, Hannah (2007). "Private enforcement of competition law in the United States-Of optimal deterrence and social costs", in Jürgen BASEDOw (ed.), Private enforcement of EC competition law. Alphen aan den rijn: Kluwer.

CARval, Suzzane (1995). La responsabilité civile dans sa fonction de peine privée. Paris: LGDJ.

Cengiz, Firat (2010). "Antitrust damages actions: lessons from American indirect purchasers' litigation”. International and Comparative Law Quarterly. vol. 59. London.

Claydon, Jeanne-Marie (1983). "Civil actions under articles 85 and 86 of the EEC Treaty: the Garden Cottage Case". European Competition Law Review. vol. 4. London.

Clough, Mark and Wilson, Adrienne (2007). "Current developments in Member States (United Kingdom)". European Competition Journal. vol. 3. Oxford.

Corral Talciani, Hernán (2003). Lecciones de responsabilidad civil extracontractual. Santiago: Editorial Jurídica de Chile.

CRANE, Daniel (2011). The institutional structure of antitrust enforcement. Oxford: OUP.

De Cossío y Corral, Alfonso (1955). El dolo en el derecho civil. Madrid: Editorial Revista de Derecho Privado.

De Ángel YágüEz, Ricardo. (2012). Daños punitivos. Cizur: Editorial Thomson Reuters.

DE ÁNGEL YÁGÜEZ, Ricardo. (1988). La responsabilidad civil. Bilbao: Universidad de Deusto.

Díez-Picazo, Luis (1999). Derecho de daños. Madrid: Editorial Civitas.

Diez Schwerter, José Luis (1997). El daño extracontractual. Jurisprudencia y doctrina. Santiago: Editorial Jurídica de Chile.

Domínguez Águila, Ramón (2010a). "Los límites al principio de reparación integral". Revista Chilena de Derecho Privado. No 15. Santiago.

Domínguez Águila, Ramón (1990). "Consideraciones en torno a la noción de daño en la responsabilidad civil. Una visión comparatista”. Revista de Derecho Universidad de Concepción. $\mathrm{N}^{\circ} 188$. Concepción.

Domínguez Hidalgo, Carmen (2010b). "El principio de reparación integral del daño y su contenido: algunas consecuencias para el derecho chileno", en Departamento de Derecho Privado Universidad de Concepción (coord.), Estudios de Derecho Civil V. Santiago: Abeledo Perrot - Legal Publishing. 
Domínguez Hidalgo, Carmen (2000). El daño moral. Santiago: Editorial Jurídica de Chile, tomo II.

DRAKE, Sara (2006). "Scope of Courage and the principle of 'individual liability' for damages: further development of the principle of effective judicial protection by the Court of Justice". European Law Review. vol. 6. London.

Easterbrook, Frank, Landes William and Posner, Richard (1980). "Contribution among antitrust defendants: a legal and economic analysis". Journal of Law and Economics. vol. 23. Chicago.

Edelman, James and Okeoghene Odudu (2002). "Compensatory damages for breach of article 81". European Law Review. vol. 27. London.

Eger, Thomas and Weise, Peter (2011). "Harm and damages as economic and legal categories in antitrust law", in Jürgen BASEDOW and Jörg Terhechte (eds.), Private enforcement of competition law. Baden-Baden: Nomos.

Epstein, Richard (2008). Cases and materials on torts. $9^{\text {th }}$ ed. New York: Aspen Publishers.

Foer, Albert (2011). "The ideal model for private enforcement of competition law", in Jürgen BASEdow and Jörg Terhechte (eds.), Private enforcement of competition law. Baden-Baden: Nomos.

Foer, Albert and Cuneo, Jonathan (2012). "Toward an effective system of private enforcement", in Albert FoER and Jonathan Cuneo (eds.), The international handbook on private enforcement of competition law. Cheltenham: Edward Elgar Publishing.

Friend, Mark and Shaw, Josephine (1984). "Damages for abuse of dominant position”. Law Quarterly Review. vol. 100. London.

Gatica Pacheco, Sergio (1959). Aspectos de la indemnización de perjuicios por incumplimiento del contrato. Santiago: Editorial Jurídica de Chile.

Gerber, David (2007). "Private enforcement of competition law: a comparative perspective", in Thomas Möllers and Andreas Heinemann, The enforcement of competition law in Europe. Cambridge: CUP.

Goldberg, Joseph and Gustafson, Dan (2012). "Obtaining evidence", in Albert Foer and Jonathan Cuneo (eds.), The international handbook on private enforcement of competition law. Cheltenham: Edward Elgar Publishing.

GonzÁlez Tissinetti, Aldo y Alejandro Micco Aguayo (2013). "Private vs public antitrust enforcement: evidence from Chile". Serie de Documentos de Trabajo. Facultad de Economía y Negocios. Universidad de Chile. Santiago.

Heinemann, Andreas (2011). "The rise of a private competition law culture: experience and visions", in Jürgen BASEDOW and Jörg Terhechte (eds.), Private enforcement of competition law. Baden-Baden: Nomos.

Herrero Suárez, Carmen (2008). "La aplicación privada del Derecho de la competencia europeo. El Libro Blanco en materia de acciones de daños y perjuicios por incumplimiento de las normas comunitarias de defensa de la competencia”. Revista de Derecho de la Competencia y la Distribución. $\mathrm{N}^{\circ}$ 3. Madrid. 
HEYDON, John (1980). "Restrictive trade practices and unfair competition", in Eugene KamenKa and Alice Erh-Soon TAY (eds.), Law and social control. London: Edward Arnold (Publishers).

Holmes, Katherine (2004). "Public enforcement or private enforcement? Enforcement of competition law in the EC and UK". European Competition Law Review. vol. 25. London.

Hylton, Keith (2003). Antitrust law. Economic theory \& common law evolution. Cambridge: CUP.

Hylton, Keith (1998). "Punitive damages and the economic theory of penalties". Georgetown Law Journal. vol. 87. Washington D.C.

JaCobs, Francis (1984). "Civil enforcement of EEC antitrust law". Michigan Law Review. vol. 82. Ann Arbor.

JaCoBs, Francis (1983) "Damages for breach of article 86 EEC". European Law Review. Vol. 8. London, pp. 353-357.

Jolowicz, John (2000). On civil procedure. Cambridge: CUP.

JonEs, Clifford (2004). "Private antitrust enforcement in Europe: a policy analysis and reality check". World Competition. vol. 27. Alphen aan den rijn.

Jones, Clifford(1999). Private enforcement of antitrust law in the EU, UK and USA. Oxford: OUP.

Komninos, Assimakis (2008). EC private antitrust enforcement: decentralised application of EC competition law by national courts. Oxford: Hart.

LANDE, Robert (2012). "Benefits of private enforcement: empirical background", in Albert Foer and Jonathan Cuneo (eds.), The international handbook on private enforcement of competition law. Cheltenham: Edward Elgar Publishing.

LANDE, Robert and Davis, Joshua (2008). "Benefits from private antitrust enforcement: an analysis of forty cases". University of San Francisco Law Review. vol. 42. San Francisco.

Landes, William and Richard Posner (1979). "Should indirect purchasers have standing to sue under the antitrust laws - An economic analysis of the rule of Illinois Brick". University of Chicago Law Review. vol. 46. Chicago.

Landes, William and Posner, Richard (1975). "The private enforcement of the law". Journal of Legal Studies. vol. 4. Chicago.

LARRAin PÁEz, Cristián (2009). "Aproximación a los punitive damages", en Carlos Pizarro Wilson (coord.), Estudios de Derecho Civil IV. Santiago: Editorial LegalPublishing.

LEVER, Jeremy (2001). "Effective private enforcement of EC antitrust rules substantive remedies: the viewpoint of an English lawyer", in Claus-Dieter EHLERMANN and Isabela ATANASIU (eds.), European competition law annual 2000: the modernisation of EC antitrust policy. Oxford: Hart.

Milutinovic, Veljko (2007). "Private enforcement", in Giuliano Amato and ClausDieter Ehlermann (eds.), EC competition law: a critical assessment. Oxford: Hart. 
Möllers, Thomas and Andreas Heinemann (2007). The enforcement of competition law in Europe. Cambridge: CUP.

MonTi, Giorgio (2007). EC competition law. Cambridge: CUP.

NAZZInI, Renato (2004). Concurrent proceedings in competition law. Oxford: OUP.

Odudu, Okeoghene and VIRGO, Graham (2009). "Remedies for breach of statutory duty". Cambridge Law Journal. vol. 68. Cambridge.

Ortíz BaQuero, Ingrid (2011). La aplicación privada del derecho de la competencia. Madrid: La Ley.

PAGE, William (1985). "The scope of liability for antitrust violations". Stanford Law Revierw. vol. 37. Stanford.

PAGE, William (1980). "Antitrust damages and economic efficiency: an approach to antitrust injury". University of Chicago Law Review. vol. 47. Chicago.

Pantaleón, Fernando (2000). "Cómo repensar la responsabilidad civil extracontractual (También de las Administraciones Públicas)", en Fernando PANTALEón (coord.), Anuario de la Facultad de Derecho de la Universidad Autónoma de Madrid. $\mathrm{N}^{\circ}$ 4. Madrid.

Paulis, Emil (2007). "Policy issues in the private enforcement of EC competition law", in Jürgen BASEDOW (ed.), Private enforcement of EC competition law. Alphen aan den rijn: Kluwer.

Peña López, Fernando (2002). La culpabilidad en la responsabilidad civil extracontractual. Granada: Editorial Comares.

Peretz, George (2005). "Enforcement and procedure before the OFT", in Tim WARD and Kassie Smith (eds.), Competition litigation in the UK. London: Sweet \& Maxwell.

Petrucci, Carlo (2008). "The issues of the passing-on defence and indirect purchasers' standing in European competition law". European Competition Law Revierw. vol. 29. London.

Pohlmann, Petra (2011). "Private losses in European competition law: public or private enforcement?", in Reiner Schulze (ed.), Compensation of private losses. The evolution of torts in European business law. Munich: Sellier European Law Publishers.

Polinsky, Mitchell (1986). "Detrebling versus decoupling antitrust damages: lessons from the theory of enforcement". Georgetown Law Journal. vol. 74. Washington D.C.

Polinsky, Mitchell and Shavell, Steven (1998). "Punitive damages: an economic analysis". Harvard Law Review. vol. 111. Cambridge (Mass.).

Polinsky, Mitchell and Shaveld, Steven (1981). "Contribution and claim reduction among antitrust defendants: an economic analysis". Stanford Law Review. vol. 33. Stanford.

Posner, Richard (2003). Economic analysis of law. $6^{\text {th }}$ ed. New York: Aspen Publishers. 
Posner, Richard (2001). Antitrust law. $2^{\text {nd }}$ ed. Chicago: University of Chicago Press.

Posner, Richard (1969). "Oligopoly and the antitrust laws: a suggested approach". Stanford Law Review. vol. 21. Stanford.

Rayment, Ben (2005). "Practice and procedure before the Competition Appeal Tribunal", in Tim WARD and Kassie SMITH (eds.), Competition litigation in the UK. London: Sweet \& Maxwell.

Reglero, Fernando (2002). "Conceptos generales y elementos de delimitación”, in Fernando Reglero (coord.), Tratado de Responsabilidad Civil. Navarra: Editorial Aranzadi, pp. 45-162.

Reich, Norbert (2005). "The 'Courage' doctrine: encouraging or discouraging compensation for antitrust injuries". Common Market Law Review. vol. 42. Alphen aan den rijn.

Roвin, Robert (2005). "Past as prelude: the legacy of five landmarks of twentiethcentury injury law for the future of torts", in Stuart MADDEN (ed.), Exploring tort law. Cambridge: CUP.

Rodger, Barry (2008). "Private enforcement of competition law, the hidden story: competition litigation settlements in the United Kingdom, 2000-2005". European Competition Law Review. vol. 29. London.

Rodger, Barry (2003). "Private enforcement and the enterprise act: an exemplary system of awarding damages". European Competition Law Review. vol. 24. London.

Roin, Howard and Christopher Monsour (2006). "Economic torts: a view from experience". Arizona Law Review. vol. 48. Tucson.

Rowan, Solène (2012). Remedies for breach of contract. A comparative analysis of the protection of performance. Oxford: OUP.

SALOP, Steven and Lawrence WHITE (1986). "Economic analysis of private antitrust litigation". Georgetown Law Journal. vol. 74. Washington D.C.

SEguRA, Francisco (2005). "Algunas consideraciones sobre la pena privada y los daños punitivos en el derecho civil chileno", en Juan Andrés VARAS y Susan Turner (eds.), Estudios de Derecho Civil. Código y Dogmática en el Sesquicentenario de la Promulgación del Código Civil (Jornadas Nacionales de Derecho Civil 2005). Santiago: Editorial LexisNexis.

SHAVELL, Steven (1987). Economic analysis of accident law. Cambridge (Mass.): HUP.

Sheehan, Duncan (2009). "Competition law meets restitution for wrongs". Law Quarterly Review. vol. 125. London.

Siragusa, Mario and Marco D'Ostuni (2007). "A reflection on some private antitrust enforcement issues", in Claus-Dieter EHLERmann and Isabela ATANASIU (eds.), European competition law annual 2006: enforcement of prohibition cartels. Oxford: Hart.

SloAne, Valentina and Julian Gregory (2005). "Introduction to the substantive provisions of EC and UK competition law", in Tim WARD and Kassie SMITH (eds.). Competition litigation in the UK. London: Sweet \& Maxwell. 
Smith, Vincent, Maton, Anthony and Campbell, Scott (2012). "England and Wales", in Albert Foer and Jonathan Cuneo (eds.), The international handbook on private enforcement of competition law. Cheltenham: Edward Elgar Publishing.

SNyder, Edward and KaUPER, Thomas (1991). "Misuse of the antitrust laws: the competitor plaintiff". Michigan Law Review. vol. 90. Ann Arbor.

Stanton, Keith (2004). "New forms of the tort of breach of statutory duty". Law Quarterly Review. vol. 120. London.

Stanton, Keith, Paul Skidmore, Michael Harris and Jane Wright (2003). Statutory torts. London: Sweet \& Maxwell.

Starck, Boris (1958). "Domaine et fondement de la responsabilité sans faute". Revue Trimestrielle de Droit Civil. Paris.

STARCK, Boris (1947). Essai d'une théorie générale de la responsabilité civile consideré en sa double fonction de garantie et de peine privée. Paris: Rodstein.

Starck, Boris, Roland, Henri \& Boyer, Laurent (1996). Obligations. Responsabilité délictuelle. 5e éd. Paris: LITEC.

Steiner, Josephine (1987). "How to make the action suit the case: domestic remedies for breach of EEC law". European Law Review. vol. 12. London.

Terhechte, Jörg (2011). "Enforcing European competition law-Harmonizing private and public approaches in a more differentiated enforcement model", in Jürgen BASEDOW and Jörg TERHECHTE (eds.), Private enforcement of competition law. Baden-Baden: Nomos.

Treitel, Guenter (2007). "Contract: in general”, en Andrew Burrows (ed.), English private law. $2^{\text {nd }}$ ed. Oxford: OUP.

Tunc, André (1989). La responsabilité civile. 2e éd. París: Economica.

Van Gerven, Walter (2007). "Private enforcement of EC competition rules in the ECJ - Courage v. Crehan and the way ahead', en Jürgen BASEDOw (ed.), Private enforcement of EC competition law. Alphen aan den rijn: Kluwer.

Vignon-Barrault, Aline (2004). Intention et responsabilité civile. Marseille: Press Universitaires d'aix Marseille, tome I - II.

Viney, Geneviève \& Jourdain, Patrice (2006). Traité de droit civil. Les conditions de la responsabilité. $3^{\mathrm{e}}$ éd. Paris: LGDJ,

Viney, Geneviève \& Jourdain, Patrice (2001). Traité de droit civil. Les effets de la responsabilité. $2^{\mathrm{e}}$ éd. Paris: LGDJ.

VIRGO, Graham (2006). The principles of the law of restitution. $2^{\text {nd }}$ ed. Oxford: OUP.

Waelbroeck, Denis and Slater, Donald (2007). “The Commission's Green Paper on private enforcement: 'Americanization' of EC competition law enforcement", en Claus-Dieter Ehlermann and Isabela Atanasiu (eds.), European competition law annual 2006: enforcement of prohibition cartels. Oxford: Hart.

WALLER, Spencer (2003). "The incoherence of punishment in antitrust". ChicagoKent Law Review. vol. 78. Chicago.

WeIr, Tony (2004). A Casebook on Tort Law. $10^{\text {th }}$ ed. London: Sweet \& Maxwell. 
Whish, Richard (2008). Competition law. $6^{\text {th }}$ ed. Oxford: OUP.

WHish, Richard (2007). "Control of cartels and other anti-competitive agreements", in Vinod Dhall (ed.), Competition law today: concepts, issues, and the law in practice. Oxford: OUP.

WHish, Richard (1994). "The enforcement of EC competition law in the domestic courts of member states", uropean Competition Law Review". vol. 15. London.

Whish, Richard and David BAiley (2012). Competition law. $7^{\text {th }}$ ed. Oxford: OUP.

WILS, Wouter (2009). "The relationship between public antitrust enforcement and private actions for damages". World Competition. vol. 31. Alphen aan den rijn.

WiLS, Wouter (2003). "Should private antitrust enforcement be encouraged?". World Competition. Vol. 26. Alphen aan den rijn.

YeunG, Karen (1998). "Privatizing competition regulation". Oxford Journal of Legal Studies. vol. 18. Oxford.

YzQUierdo Tolsada, Mariano (2001). Sistema de responsabilidad civil, contractualy extracontractual. Madrid: Editorial Dykinson.

\section{Normas citadas}

Antitrust Criminal Penalty Enhancement and Reform Act, de 2004.

252 Clayton Act, de 1914, 15 U.S.C. § 15(a).

Competition Act, de 1998.

Courts and Legal Services Act, de 1990

DFL $\mathrm{N}^{\circ} 1$ de 2005, que fijó el texto refundido, coordinado y sistematizado del DL N 211 de 1973, Diario Oficial, 7 de marzo de 2005.

Enterprise Act, de 2002.

Libro Blanco sobre acciones de daños y perjuicios por incumplimiento de las normas comunitarias de defensa de la competencia, COM (2008) 165 final, Diario Oficial de la Unión Europea, 2 de abril de 2008.

Propuesta de Directiva del Parlamento Europeo y del Consejo relativa a determinadas normas por las que se rigen las demandas por daños y perjuicios por infracciones de las disposiciones del Derecho de la competencia de los Estados miembros y de la Unión Europea, COM (2013) 404 final, Diario Oficial de la Unión Europea, 11 de junio de 2013.

Sherman Act, de 1890, 15 U.S.C.

Statute Law (Repeals) Act, de 1969

Statute of Monopolies, de 1623

Tratado de Funcionamiento de la Unión Europea, Diario Oficial de la Unión Europea, 30 de marzo de 2010.

Tratado de Lisboa, Diario Oficial de la Unión Europea, 17 de diciembre de 2007.

Tratado de Roma de 1957, constitutivo de la Comunidad Europea. 


\section{Jurisprudencia citada}

\section{Chilena}

Cementa S.A. con James Hardie Fibrocementos Ltda (2009): 26 $6^{\circ}$ Juzgado Civil de Santiago, 24 de abril de 2009 (acción de indemnización de perjuicios por infracción del DL N ${ }^{\circ}$ 211), rol 13.272-2007

Contra Berenguela Orellana, Javier (1998): Corte Suprema, 2 de diciembre de 1998 (delito de violación; acción de indemnización de perjuicios), Fallos del Mes, $N^{\circ} 481$, Santiago, 1998.

Contra Celedón Silva, Jaime (1984): Corte Suprema, 19 de abril de 1984 (delito de injuria; acción de indemnización de perjuicios), Revista de Derecho y Jurisprudencia, tomo 81, Santiago, 1984, sec. $4^{\mathrm{a}}$.

Contra Gallardo Díaz, Manuel (1987): Corte Suprema, 14 de septiembre de 1987 (acción de indemnización de perjuicios), Revista de Derecho y Jurisprudencia, tomo 84 , Santiago, 1987, sec. $4^{\mathrm{a}}$.

Contra Monroy Izquierdo, Mario (1999): Corte Suprema, 19 de mayo de 1999 (acción de indemnización de perjuicios), Fallos del Mes, N 486, Santiago, 1999.

Contra Suárez S., Roberto (1973): Corte de Apelaciones de Santiago, 3 de junio de 1973 (acción de indemnización de perjuicios), Revista de Derecho y Jurisprudencia, tomo 70, Santiago, 1973, sec. $4^{\mathrm{a}}$.

Contra Vergara Pérez, José Eugenio (1972): Corte Suprema, 6 de noviembre de 1972 (delito de contrabando; acción de indemnización de perjuicios), Revista de Derecho y Jurisprudencia, tomo 69, Santiago, 1972, sec. $4^{\mathrm{a}}$.

Curaqueo Antiman, Sergio con Congregación del Santísimo Redentor (1990): Corte de Apelaciones de Santiago, 26 de septiembre de 1990 (acción de indemnización de perjuicios), Gaceta Jurídica, № 123, Santiago, 1990.

Fueyo, Ceferino con Urbistondo, Vicente (1953): Corte Suprema, 14 de abril de 1953 (acción de indemnización de perjuicios), Revista de Derecho y Jurisprudencia, tomo 50, Santiago, 1953, sec. $4^{\mathrm{a}}$.

Madariaga con Ferrocarriles del Estado (1928): Corte Suprema, 14 de abril de 1928 (acción de indemnización de perjuicios), Revista de Derecho y Jurisprudencia, tomo 26, Santiago, 1929, sec. $1^{\mathrm{a}}$.

Philip Morris Chile Comercializadora Limitada con Compañía Chilena de Tabacos S.A. (2011): $10^{\circ}$ Juzgado Civil de Santiago, 25 de enero de 2010 (acción de indemnización de perjuicios por infracción del DL No 211), rol 19.655-2009; Corte de Apelaciones de Santiago, 8 de noviembre de 2011 (recurso de apelación), rol 1520-2010; Corte Suprema, 25 de julio de 2013, rol 1.339-2012 (recursos de casación en el fondo)

Pivcevic y otros con LAN Chile (2006): $4^{\circ}$ Juzgado Civil de Santiago, 22 de junio de 2000, rol 4.831-97; Corte de Apelaciones de Santiago, 14 de julio de 2004, rol 5.954-1999; y Corte Suprema, 27 de diciembre de 2006 (acción de indemnización de perjuicios por infracción del DL No 211), rol 5.835-2004 
Porzio v. de G con Shell Mex Chile Ltda. (1941): Corte Suprema, 26 de agosto de 1941 (acción de indemnización de perjuicios), Revista de Derecho y Jurisprudencia, tomo 40, Santiago, 1943, sec. $1^{\mathrm{a}}$.

Producción Química y Electrónica Quimel S.A. con James Hardie Fibrocementos Ltda (2009): $26^{\circ}$ Juzgado Civil de Santiago, 23 de junio de 2009 (acción de indemnización de perjuicios por infracción del DL No 211), rol 2.191-2007.

Servicio Agrícola Ganadero (1993): Corte de Apelaciones de Santiago, 27 de diciembre de 1993 (acción de indemnización de perjuicios), Gaceta Jurídica, $\mathrm{N}^{\circ}$ 162, Santiago, 1993.

Servicio Nacional del Consumidor con Farmacias Cruz Verde S.A. y Otras (2013): $10^{\circ}$ Juzgado Civil de Santiago, 10 de mayo de 2013 (acción de indemnización de perjuicios por infracción del DL No 211), rol 1.940-2013; Corte de Apelaciones de Santiago, rol 4.038-2013 (recurso de apelación).

Sociedad General de Comercio S.A. con Banco Español-Chile (1954): Corte Suprema, 16 de octubre de 1954 (acción de indemnización de perjuicios), Revista de Derecho y Jurisprudencia, tomo 51, Santiago, 1954, sec. $1^{\mathrm{a}}$.

Soto con Banco Santander (2003): Corte de Apelaciones de Santiago, 1 de septiembre de 2003 (acción de indemnización de perjuicios), Gaceta Jurídica, $\mathrm{N}^{\circ}$ 279, Santiago, 2003; Corte Suprema, 13 de noviembre de 2003 (casación en el fondo), Gaceta Jurídica, N 281, Santiago, año.

254 Sound Colour con United International Pictures Chile (2009): $10^{\circ} \mathrm{Juzgado}$ Civil de Santiago, 30 de diciembre de 2005, rol 782-2004, confirmada por Corte de Apelaciones de Santiago, 30 de junio de 2009 (acción de indemnización de perjuicios por infracción del DL No 211), rol 1.361-2006.

UIP Chile Ltda. y Andes Films S.A. contra Dictamen No 1.277 Comisión Preventiva Central (2005): Tribunal de Defensa de la Libre Competencia, Sentencia $\mathrm{N}^{\circ}$ 16, 20 de mayo de 2005 (avocación en recurso de reclamación).

Wessel Duval y Cía. con Errázuriz (1927): Corte Suprema, 15 de noviembre de 1927 (acción de indemnización de perjuicios; casación en el fondo), Revista de Derecho y Jurisprudencia, tomo 25, Santiago, (1928), sec. $1^{\mathrm{a}}$.

\section{Estadounidense}

Associated Industries of New York State, Inc. v. Ickes (1943): Corte de Apelaciones del Segundo Circuito (apelación), 8 de febrero de 1943, 134 F.2d 694 ( $2^{\text {nd }}$ Cir. 1943).

Associated General Contractors of California v. California State Council of Carpenters (1983): Corte Suprema, 22 de febrero de 1983 (certiorari), 459 U.S. 519 (1983).

Atlantic Richfield Co. v. USA Petroleum Co. (1990): Corte Suprema, 14 de mayo de 1990 (certiorari), 495 U.S. 328 (1990).

Bigelow v. RKO Radio Pictures (1946): Corte Suprema, 25 de febrero de 1946 (certiorari), 327 U.S. 251 (1946). 
Brunswick Corp. v. Pueblo Bowl-O-Mat, Inc. (1977): Corte Suprema, 25 de enero de 1977 (certiorari), 429 U.S. 477 (1977).

California v. ARC America Corp (1989): Corte Suprema, 18 de abril de 1989 (apelación), 490 U.S. 93 (1989).

Cargill, Inc. v. Monfort of Colorado, Inc. (1986): Corte Suprema, 9 de diciembre de 1986 (certiorari), 479 U.S. 104 (1986).

Freeman v. San Diego Asśn of Realtors (2003): Corte de Apelaciones del Noveno Circuito, 10 de marzo de 2003 (apelación), 322 F.3d 1133, 9th Cir. (2003).

Hanover Shoe, Inc. v. United Shoe Machinery Corp (1968): Corte Suprema, 17 de junio de 1968 (certiorari), 392 U.S. 481 (1968).

Illinois Brick Co. v. Illinois (1977): Corte Suprema, 9 de junio de 1977 (certiorari), 431 U.S. 720 (1977).

J. Truett Payne Company, Inc. v. Chrysler Motors Corporation (1981): Corte Suprema, 18 de mayo de 1981 (certiorari), 451 U.S. 557 (1981).

Kreager v. GE (1974): Corte de Apelaciones del Segundo circuito, 13 de mayo de 1974 (apelación), 497 F.2d 468 (2d Cir.), certiorari denegado, 419 U.S. 861 (1974).

Perma-Life Mufflers, Inc. v. International Parts Corp (1968): Corte Suprema, 10 de junio de 1968 (certiorari), 392 U.S. 134 (1968).

Radovich v. National Football League (1957): Corte Suprema, 25 de febrero de 1957 (certiorari), 352 U.S. 445 (1957).

Story Parchment Co. v. Paterson Parchment Paper Co. (1931): Corte Suprema, 24 de febrero de 1931 (certiorari), 282 U.S. 555 (1931).

Texas Industries, Inc. v. Radcliff Materials, Inc. (1981): Corte Suprema, 26 de mayo de 1981 (certiorari), 451 U.S. 630 (1981).

U.S. v. Topco Associates, Inc. (1972): Corte Suprema, 29 de marzo de 1972 (apelación), 405 U.S. 596 (1972).

Wall Prods. Co. v. National Gypsum (1973): Corte del Distrito del Norte de California, 13 de abril de 1973 (acción privada por ilícito anticompetitivo), 357 F.Supp 832 (N.D. Cal. 1973).

Zenith Radio Corporation v. Hazeltine Research, Inc. (1969): Corte Suprema, 19 de mayo de 1969 (certiorari), 395 U.S. 100 (1969).

\section{Europea}

Courage Ltd. v. Crehan (2001): Tribunal Europeo de Justicia, 20 de septiembre de 2001 (cuestión prejudicial), [2002] QB 507

Francovich v. The Republic of Italy (1991): Tribunal Europeo de Justicia, 19 de noviembre de 1991 (responsabilidad de Estados miembros para con individuos), [1993] 2 CMLR 66

Manfredi v. Lloyd Adriatico Assicurazioni SpA (2006): Tribunal Europeo de Justicia, 13 de julio de 2006 (cuestión prejudicial), casos C-295 a C-298/04 [2006] ECR I-6619 
Pfleiderer AG v. Bundeskartellamt (2011): Tribunal Europeo de Justicia, 14 de junio de 2011 (cuestión prejudicial), [2011] 5 CMLR 219.

\section{Francesa}

Cass. Req., 9.11.1871, D.P., 1871, 1, p. 211

Cass. com, 18.4.1958, D., 1959, p. 87, n. Derrida

Cass. com, 21.3.1989, Bull. civ., IV, $\mathrm{N}^{\circ} 97$

Cass. com., 7.4.1998, D., 1999, somm., p. 128, obs. Schmidt-Szalewski

Cass. com, 3.5.2000, D., 2001, somm., p. 1312, obs. Serra

Cass. com., 12.5.2004, Gaz. Pal., 2005, somm., p. 571, obs. Guével.

Inglesa

AAH Pharmaceuticals Ltd $v$. Pfizer Ltd (2007): High Court (Chancery Division), 5 de marzo de 2007 (injunction), [2007] EWHC 565.

Albion Water Ltd v. Dr Cymru Cyfyngedig (2010): Competition Appeal Tribunal, 8 de diciembre de 2010 (acción de indemnización de perjuicios), [2010] CAT 30.

Albion Water Limited v. Dr Cymru Cyfyngedig: Competition Appeal Tribunal, 28 de marzo de 2013 (acción de indemnización de perjuicios), [2013] CAT 6.

American Cyanamid Co. v. Ethicon Ltd. (1975): Cámara de los Lores, 5 de enero de 1975 (apelación), [1975] AC 396.

Arkin v. Borchard Lines Ltd (2005): High Court (Queen's Bench Division), 10 de abril de 2003 (acción de indemnización de perjuicios), [2003] EWHC 687.

Attheraces Ltd. v. British Horseracing Board Ltd. (2007): High Court (Chancery Division, juez Etherton), 21 de diciembre de 2005 (demanda privada por ilícito anticompetitivo), [2005] EWHC 3015 Corte de Apelaciones, 2 dwe febrero de 2007 (apelación), [2007] EWCA Civ 38.

BCL Old v. Aventis (2005): Competition Appeal Tribunal, 28 de enero de 2005 (acción de indemnización de perjuicios), [2005] CAT 2.

Boissevain v. Weil (1950): Cámara de los Lores, 21 de marzo de 1950 (apelación), [1950] AC 327.

Bookmakers Afternoon Greyhound Services Ltd v. Amalgamated Racing Ltd (2009): Corte de Apelaciones, 28 de julio de 2009 (apelación), [2009] EWCA Civ. 750.

Callery v. Gray (2001): Corte de Apelaciones, 17 de julio de 2001 (apelación), [2001] EWCA Apleación civil. 1117.

Claritas (U.K.) Ltd. v. The Post Office (2000): High Court (Chancery Division), 2 de noviembre de 2000 (demanda privada por ilícito anticompetitivo), [2001] UKCLR 2.

Claymore Dairies Ltd. v. OFT (2004): Competition Appeal Tribunal, 24 de septiembre de 2004 (revelación de información), [2004] CAT 16. 
Crehan v. Inntrepreneur Pub Co (CPC) (2006): Cámara de los Lores, 19 de julio de 2006 (apelación), [2007] 1 A.C. 333.

Darcy v. Allein (1572): High Court, 1 de enero de 1572 (monopolios), (1602) 77 ER 1260.

Devenish Nutrition v. Sanofi-Aventis (2008): High Court (Chancery Division, juez Lewison), 19 de octubre de 2007 (demanda de daños punitivos y restitutorios), [2008] 2 All ER 249; Corte de Apelaciones, 14 de octubre de 2008 (apelación), [2009] 3 All ER 27.

Enron Coal Services Limited (In Liquidation) v. English Welsh \& Scottish Railway Ltd (2010): Competition Appeal Tribunal, 9 de febrero de 2010 (damages claim), [2009] CAT 36; Court of Appeal, 19 de enero de 2011 (appeal), [2011] EWCA Civ 2.

Garden Cottage Foods Ltd. v. Milk Marketing Board (1983): Cámara de los Lores, 23 de junio de 1983 (apelación), [1984] 1 AC 130.

Gibbs Mew Plc v. Gemmell (1998): Corte de Apelaciones, 22 de Julio de 1998 (apelación), [1999] ECC 97) .

Healthcare at Home v. Genzyme Ltd (2006): Competition Appeal Tribunal, 15 de noviembre de 2006 (acción de indemnización de perjuicios), ([2006] CAT 29.

Hendry v. World Professional Billiards and Snooker Assoc. Ltd. (2001): High Court (Chancery Division), 5 de octubre de 2001 (demanda privada por ilícito anticompetitivo), [2002] UKCLR 5.

Holman v. Johnson (1775): Lord Mansfield, 5 de julio de 1775 (demanda de cumplimiento de contrato), (1775) 1 Cowp. 341.

Holleran v. Daniel Thwaites Plc (1988) : High Court (Chancery Division), 1 de julio de 1988 (demanda privada por ilícito anticompetitivo), [1989] 2 CMLR 917.

Inntrepreneur Estates Ltd. v. Mason (1993) : High Court (Queen's Bench Division), 11 de marzo de 1993 (apelación), [1993] 2 CMLR 293.

Kleinwort Benson Ltd. v. Birmingham CC (1996): Corte de Apelaciones, 9 de mayo de 1996 (restitución), [1997] QB 380.

Kuddus v. Chief Constable of Leicestershire (2001): Cámara de los Lores, 7 de junio de 2001 (apelación), [2002] 2 AC 122.

Langton v. Hughes (1813): High Court, 21 de junio de 1813 (demanda de cumplimiento de contrato), (1813) $1 \mathrm{M} \& S 593$.

Marks \& Spencer Plc v. Commissioners of Customs and Excise (1998): High Court (Queen's Bench Division), 21 de diciembre de 1998 (restitución), [1999] 1 CMLR 1152.

Mitchell v. Reynolds (1712): High Court, 1 de enero de 1712 (demanda de cumplimiento de contrato), (1712) 88 ER 637.

Rio Tinto Zinc Corp. v. Westinghouse (1977): Cámara de los Lores, 1 de diciembre de 1977 (apelación), [1978] AC 547.

Rookes v. Barnard (1964): Cámara de los Lores, 21 de enero de 1964 (intimidación y daños punitivos), [1964] AC 1129. 
Travel Group PLC (in liquidation) v. Cardiff City Transport Services Limited (2012): Competition Appeal Tribunal, 5 de julio de 2012 (acción de indemnización de perjuicios), [2012] CAT 19.

Wireless Group Plc v. Radio Joint Audience Research Ltd. (2004): High Court (Chancery Division), 16 de diciembre de 2004 (demanda privada por ilícito anticompetitivo), [2005] UKCLR 203. 